\title{
Patrón de asentamiento tardío y ecología cultural del alto Qaracha
}

\section{Late pattern settlement and cultural ecology from upper Qaracha}

\author{
Marco Taquiri González \\ https://orcid.org/oooo-0002-0372-3648 \\ Universidad Nacional San Luis Gonzaga \\ marco.takiri@gmail.com \\ Juan Tello Quito \\ https://orcid.org/oooo-0003-3833-5060 \\ Universidad Nacional San Luis Gonzaga \\ juan.tello.quito@gmail.com

\section{Ricardo González Alvarado} \\ https://orcid.org/0000-0001-9027-1688 \\ Universidad Nacional San Luis Gonzaga \\ gonzalezalvaradoricardo@gmail.com
}

\section{RESUMEN}

El presente artículo muestra los resultados del poblamiento prehispánico tardío de la cuenca alta del Qaracha en la meseta altiplánica disectada de la región central de Ayacucho (3000 - 4000 m s. n. m.). El registro arqueológico permitió evaluar la extensión y diversidad de la ocupación territorial altoandina a una escala local y su relación con el medio ecológico. El poblamiento tardío de este territorio estuvo concentrado en grandes aldeas que generalmente suelen tener un núcleo central habitable con arquitectura de piedra. Los núcleos habitables presentan patrones homogéneos de tecnología constructiva y diseño espacial de grandes conjuntos de viviendas con corrales, terrazas y estructuras funerarias. Se discute la función te- 
rritorial de las aldeas y se propone que este tipo de asentamientos constituyen una evidencia tangible para caracterizar un modelo de vida aldeana y la dinámica territorial prehispánica a una escala local, en un periodo de latente conflicto.

Palabras clave: patrón de asentamiento, ecología cultural, alto Qaracha.

\section{ABSTRACT}

This article shows the results of the late pre-Hispanic settlement of the upper Qaracha basin in the dissected plateau of the central region of Ayacucho (3000 - 4000 meters above sea level). The archaeological record made it possible to evaluate the extension and diversity of the high Andean territorial occupation at a local scale and its relationship with the ecological environment. The late settlement of this territory was concentrated in large villages that generally have a central habitable nucleus with stone architecture. The habitable nucleus present homogeneous patterns of construction technology and spatial design of large housing complexes with corrals, terraces and funeral structures. The territorial function of the villages is discussed and it is proposed that this type of settlements constitute tangible evidence to characterize a model of village life and pre-Hispanic territorial dynamics at a local scale, in a period of latent conflict.

Keywords: settlement pattern, cultural ecology; upper Qaracha.

ReCiBIDO: 01/07/2020 - ACEPTADO: 11/08/2021 - PUbliCADO: 25/11/2021

\section{INTRODUCCIÓN}

El artículo se enfoca en el estudio de la estructura territorial de los pueblos del alto Qaracha afines a las identidades étnicas del Periodo Intermedio Tardío (1100 - 1400 d. C.) y Horizonte Tardío (1400 - 1532 d. C.). Esta zona de muestreo tiene características altoandinas con un amplio espectro de recursos naturales que hacen de este lugar un escenario adecuado para comprender la dispersión de la ocupación humana y su ecología cultural. Se da un interés particular en entender la red de poblamiento prehispánico y su relación con el entorno ambiental para determinar la función y estructura territorial de los pueblos y aldeas principales del Alto Qaracha, por lo cual se realizó prospecciones extensivas en ambas márgenes del valle, para identificar vestigios de yacimientos prehispánicos y su acondicionamiento rural a un medio agreste, pero de alta densidad habitable. Antes de la anexión inca, estos parajes estaban habitados por pueblos rukanas contiguos al foco principal andamarca del valle de Sondondo, el estudio territorial del área señalada podría acercarnos a entender una identidad cultural rukana de pueblos naturalmente defendibles relacionados con las nuevas estrategias de poblamiento post wari, diseminados en el límite superior del piso ecológico keswa por sobre el piso del valle. La investigación 
se formula a partir de la necesidad de obtener sustento arqueológico sobre estrategias de poblamiento prehispánico tardío relacionados con los nuevos desafíos de explotación, producción y consumo de bienes materiales en un contexto álgido de atomización social y alta inestabilidad política.

\section{EL ALTO QARACHA}

\subsection{El curso alto del río Qaracha: Ubicación y extensión}

El río Qaracha discurre en una altiplanicie de la región sur de Ayacucho, dentro del ámbito de la Cordillera Occidental de los Andes Centrales. La escorrentía del Qaracha es parte del área interfluvial de la Divisoria Continental de aguas, al levante de la cadena Occidental que origina la vertiente Atlántica. La cuenca del río Qaracha morfológicamente está formada por una superficie irregular que corresponde a la puna de alta montaña, con arroyos y ríos en constante proceso de incisión que forman las quebradas de puna y los valles angostos keswas, hasta formar el cañón principal de río principal Qaracha, tributario del río Pampas.

El curso alto del río Qaracha es longitudinal y dendrítico (figura 1), abarca parte del territorio de la Provincia de Huancasancos, desde el naciente del río Urabamba en la meseta altiplánica, hasta la confluencia del río Lucanamarca por su margen izquierda. Geográficamente se enmarca entre los $13^{\circ} 48^{\prime}$ latitud S y $74^{\circ} 20^{\prime}$ longitud $\mathrm{O}$, en el extremo septentrional; y entre los $14^{\circ} 00^{\prime}$ latitud S y longitud $74^{\circ} 20^{\prime} \mathrm{O}$, del extremo meridional. Sobre este espacio de cerca de $466.00 \mathrm{~km} 2$ se despliegan distintas ecozonas naturales que favoreció la formación de una red de poblamiento prehispánico de aldeas tardías con alta densidad habitable y acondicionamientos agropastoriles en un espacio altoandino.

\subsection{Geomorfología}

El área de estudio presenta tres unidades geomorfológicas, cada uno de los cuales, con características particulares definidos en base a su altitud, a considerar: Altiplanicies, mesetas disectadas y valles interandinos (INGEMMET, 1996). La altiplanicie (4.000 - $4.500 \mathrm{~m} \mathrm{s.} \mathrm{n.} \mathrm{m.)} \mathrm{corresponde} \mathrm{a} \mathrm{la} \mathrm{meseta} \mathrm{altiplánica} \mathrm{o} \mathrm{superficie} \mathrm{de} \mathrm{puna}$ que en sus confines se elevan las zonas glaciadas; la meseta disectada (3.000 - 4.000 m s. n. m.) es la unidad geográfica de amplia exposición del área, corresponde a la puna baja de modelado típicamente glaciar altoandino, profundamente disectada por los ríos que forman quebradas y valles en la Cuenca de los ríos Qaracha y Pampas, respectivamente; la superficie de meseta es de relieve suave y ondulado de flancos de poca pendiente; y finalmente, el valle interandino ${ }^{1}(3.000-3.500 \mathrm{~m} \mathrm{s.} \mathrm{n.} \mathrm{m.)}$ de relieve profundo y encañonado, las partes altas muestran perfiles transversales

1. El valle interandino del río Pampas y sus afluentes corresponden al área de la meseta disectada. A esta unidad geomorfológica pertenece el drenaje del río Qaracha y sus tributarios que recogen la escorrentía de la mayor parte de la zona altoandina. 


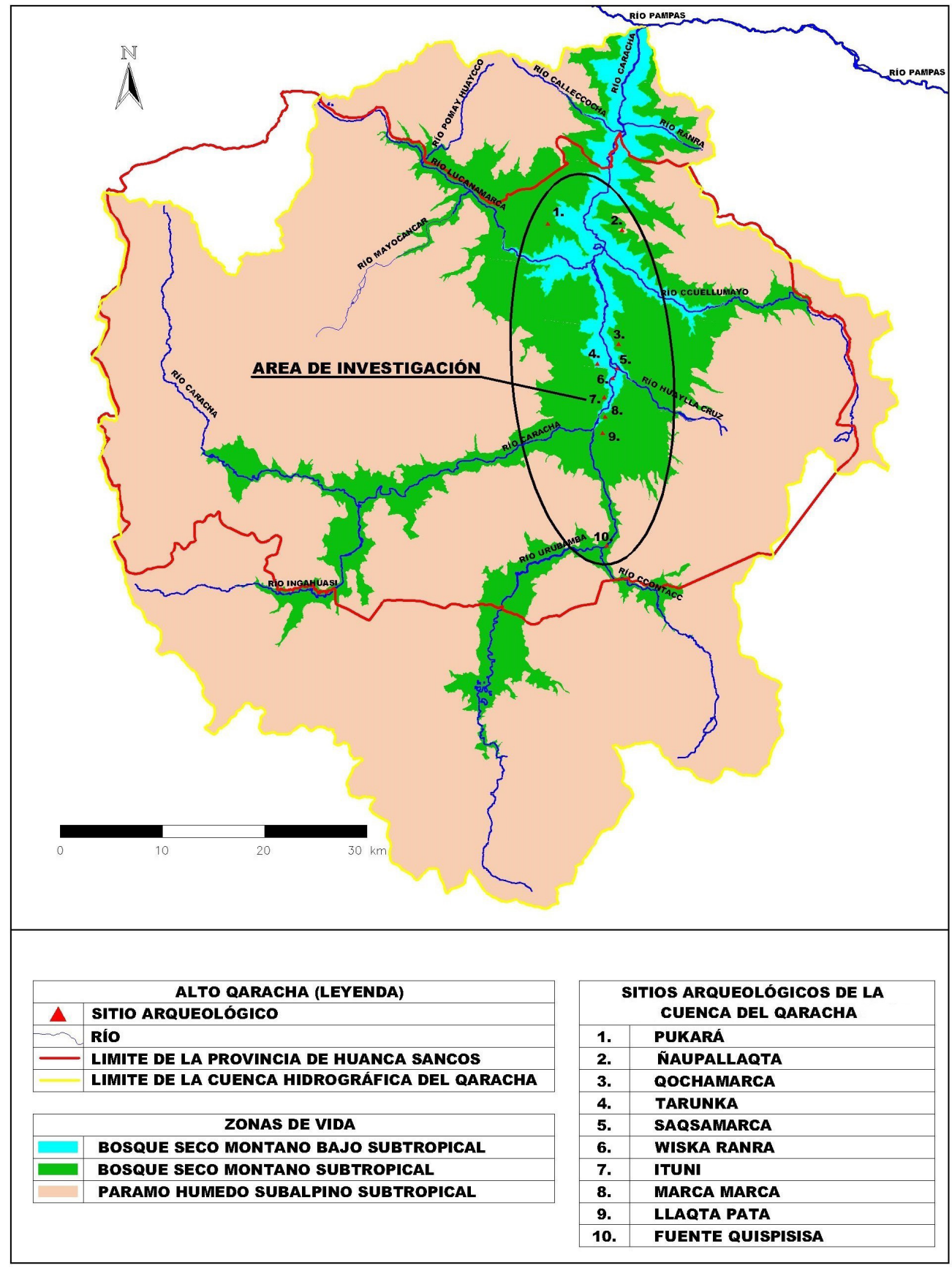

Figura 1. Mapa de ubicación del Alto Qaracha. (Elaborado por Ricardo González). 


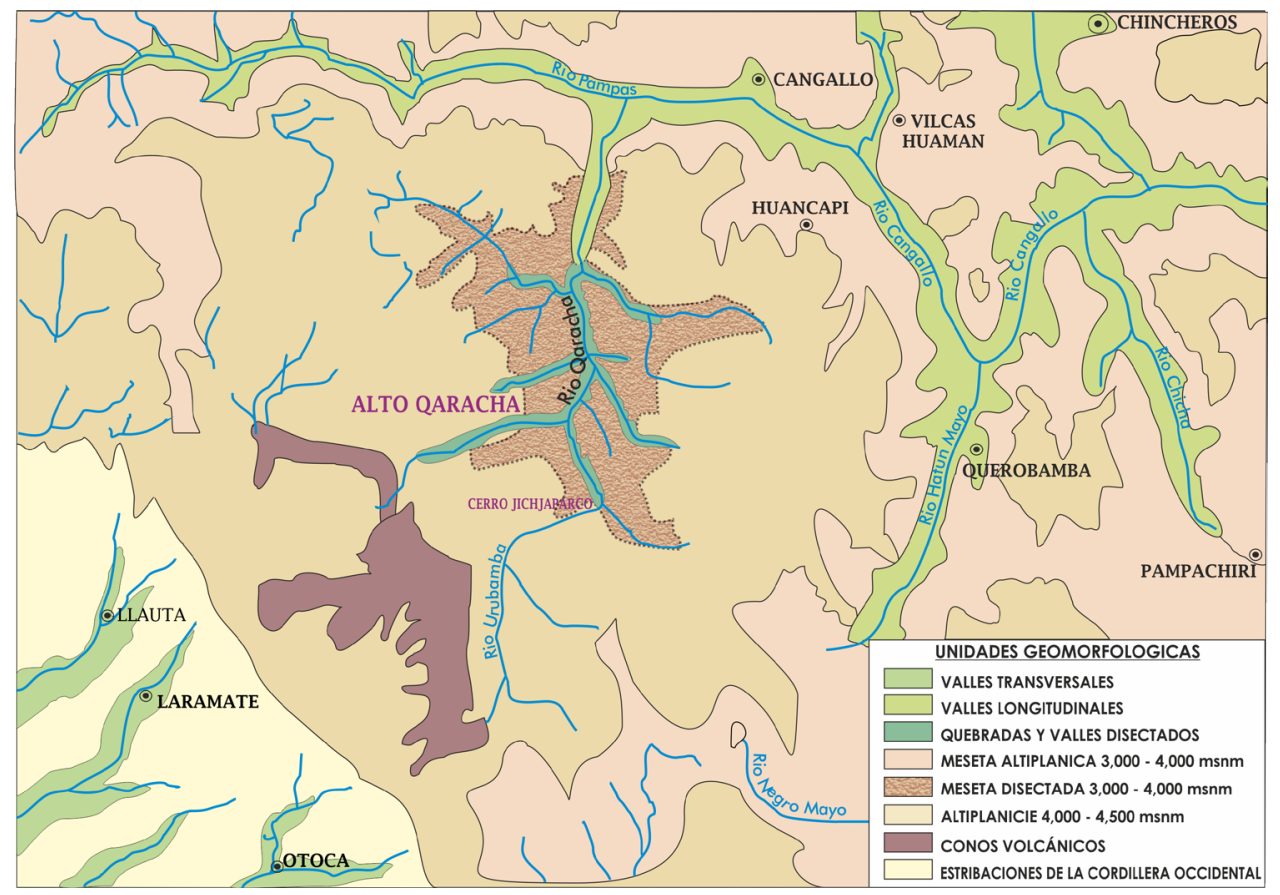

Figura 2. Geomorfología del Alto Qaracha, en el ámbito de la Cordillera Occidental de los Andes Centrales de la región sur de Ayacucho. (Elaborado por Marco Taquiri).

abiertos que corresponden a la etapa valle; en las partes inferiores los valles son profundos con pisos de fuerte gradiente y anchos variables, que reflejan una constante incisión de fondo muy activo, correspondiente de la etapa cañón.

\subsection{Cartografía etnohistórica del Alto Qaracha}

Desde el punto de vista histórico, en el área actual de la provincia de Huancasancos proliferaban grupos étnicos originarios y traspuestos tardíamente por los incas, estos grupos originarios posiblemente formaban parte de los antamarcas que a su vez era una provincia grande de la macroetnia rukana ${ }^{2}$. El foco de poblamiento de la parcialidad antamarca estaba establecido en el valle del río Sondondo, así mismo existían colonias establecidas fuera del área nuclear y abarcó los drenajes costeros de Nasca y Acarí hasta la hoya del río Pampas, el ejercicio territorial era transversal y disperso por lo que no es posible distinguir con claridad fronteras étnicas entre las provincias de la macroetnia rukana.

2. La macroetnia rukana estaba disperso en tres grandes repartimientos, cada uno de ellos con una cabecera principal y controlaban territorios distantes a su núcleo central. Los focos de poblamiento de estos grupos se establecieron en la cuenca alta del río Acarí y río Grande (rukanas), en el valle del río Sondondo (andamarcas) y el valle del río Chicha-Soras (Soras). 
A partir del abanico cartográfico que ofrece las Relaciones Geográficas de Indias ${ }^{3}$, se ha logrado aproximar la ubicación del alto Qaracha al territorio de los rukana antamarcas. Esto se ve reforzada por la ubicación de dos poblados actuales de origen colonial, reducidos sobre las márgenes del río Qaracha. Se trata del distrito de Sacsamarca que en la temprana época colonial aparece como Curato de Sacsamarca perteneciente al corregimiento de Vilcashuamán de la jurisdicción de Huamanga: "Dista este pueblo de Zanco veinte leguas de la ciudad de Guamanga, a cuya juridiccion está sujeto, y el dicho pueblo de Sacsamarca" (Carbajal, 1881, p. 152). La ubicación exacta del distrito Sancos, quedaba en la banda izquierda del Qaracha: "Dista este pueblo de Zanco [curato] del pueblo de Chuschi ocho leguas, y el de Sacsamarca tiene por la otra banda [del río Qaracha]" (id. 1881, p. 152). El río principal de ambos curatos, aparece como el río Urabamba: "Pasa por entre estos dos pueblos el río que llaman Urabamba, el cual es medianamente caudaloso, y ocho leguas de este pueblo se junta con el dicho río de Choclococha [río Pampas]" (ibíd. 1881, p. 153). Actualmente el río principal de la provincia de Huancasancos es el Qaracha, esto supondría que en la época prehispánica este río se denominó Urabamba, relegándose hoy este título para un tributario del curso alto del Qaracha.

En este sentido, el área de estudio podría caer dentro del patrón multiétnico de poblados periféricos rukana establecidos en el alto Qaracha. Esta idea se ve reforzada por la ubicación de dos poblados antamarcas - Alcamenca y Huamanquiquia - en el curso inferior del río Qaracha, cerca del valle del río Pampas. Estas regiones periféricas, especialmente la cuenca del río Qaracha, pueden considerarse contiguas a la ocupación principal andamarca del valle de Sondondo. Tras su incorporación al Tawantinsuyo, este territorio fue alterado con la política inca de inserción de mitimaes foráneos. Estos territorios, se incorporaron a la provincia administrativa inca de Vilcashuamán, tal cómo fueron hallados por los españoles durante su arribo a esta región: "Vilcas, que es un tambo real a once leguas de esta ciudad [Huamanga], yendo hacia el Cuzco. Este gobernaba cuarenta leguas de tierra, desde Uramarca, que es de aquel cabo de Vilcas seis leguas, hasta Acos, questá junto al valle de Xauxa" (de la Bandera, 1881, p. 99).

3. Este documento colonial, escrito a mediados del siglo XVI, contiene la relación de las visitas de Monzón en 1586 al territorio de la macroetnia rukana, que en la segunda mitad del siglo XVI estaba formado por tres repartimientos: Soras, Rukanas y Rukana - Andamarcas. En la década de 1580, Los Soras, Lucanas y Lucanas Andamarcas formaban una sola unidad administrativa, un corregimiento que se aproximaba a los límites de la moderna provincia de Lucanas (Meddens y Schreiber, 2010). El administrador de este corregimiento fue precisamente, Luis de Monzón: "Corregidor por su Magestad desta provincia de Rucanas y Soras" (1881a, p. 169). Las visitas dan respuestas a extensos cuestionarios sobre cada repartimiento, su historia local y los acontecimientos históricos ocurridos antes y después de la presencia inca en la región. 

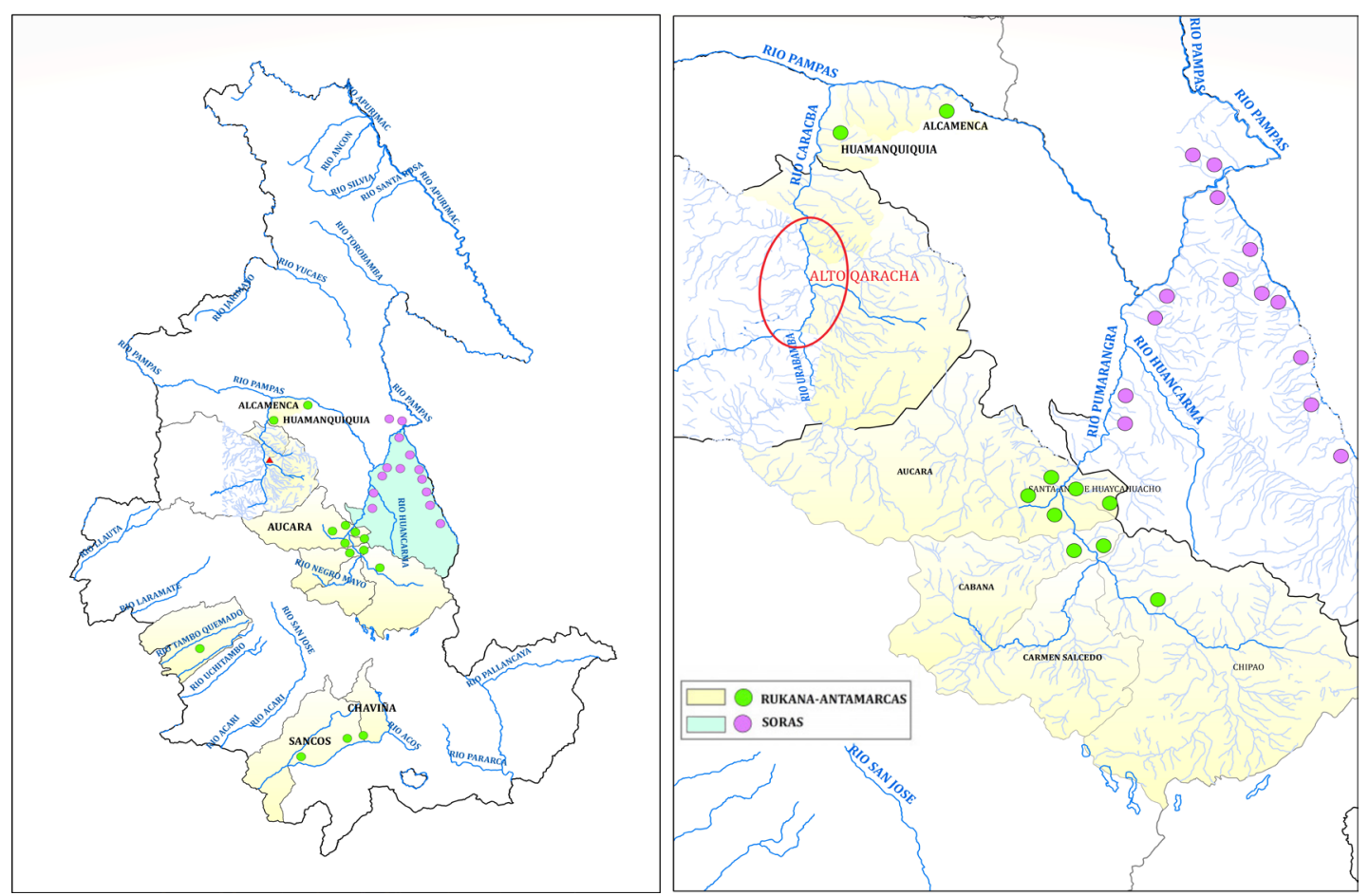

Figura 3. Dispersión de los grupos étnicos PIT y HT en el siglo XVI, al sur de Ayacucho. (Fuente: Relación de Visitas de Luis de Monzón en 1586 [1881]). (Elaborado por Marco Taquiri).

\subsection{Antecedentes de estudios arqueológicos}

Las investigaciones en la cuenca del río Qaracha y sus afluentes son limitados, los estudios arqueológicos previos en este espacio revelan una proliferación de asentamientos que surgieron en una época de gran alteración política y notable diversidad cultural. Las primeras exploraciones de Valdez y Vivanco (1994) reportan poblados post wari instalados en la cima de la cadena de montañas del río Pampas y Qaracha. Vivanco, en sucesivos estudios $(1998,2003,2005,2013)$ sobre el poblamiento prehispánico del río Qaracha identifica sitios fortificados con muros defensivos y estructuras de planta circular sin aparente planificación, estos poblados ocupan lugares estratégicos de carácter defensivo y de amplio dominio visual del entorno. Para la zona altoandina, Cavero (2010) reporta la presencia de ushnus de altura, la distribución equidistante de estas plataformas ceremoniales está relacionado con el control territorial y demuestra el dominio inca de la región en el Horizonte Tardío.

Las recientes exploraciones de Contreras et al. (2012) en el curso alto del río Qaracha, han identificado los depósitos de obsidiana Quispisisa ${ }^{4}$ en el cerro Jiccha Parc-

4. El tipo geoquímico Quispisisa fue identificado inicialmente por Burger y Asaro $(1977,1979)$. La obsidiana de la fuente Quispisisa recién reubicada por Burger y Glascock (2000) se encuentra sobre las paredes del río Urabamba, en el dren alto río Qaracha. 
co: "Se trata de un acantilado erosionado ubicado en el lado este del río Urabamba" (p. 186). En este lugar se han documentado evidencias de explotación de obsidiana Quispisisa a gran escala. Este material se ha recuperado en numerosos contextos arqueológicos a lo largo de los Andes centrales, sin embargo, el patrón de ese intercambio y explotación no es tan conocido para el Periodo Intermedio Tardío. Algunos poblados tardíos identificados se ubican en el rango de alcance de la fuente Quispisisa, los restos de obsidiana en estos sitios demostrarían su explotación en este período.

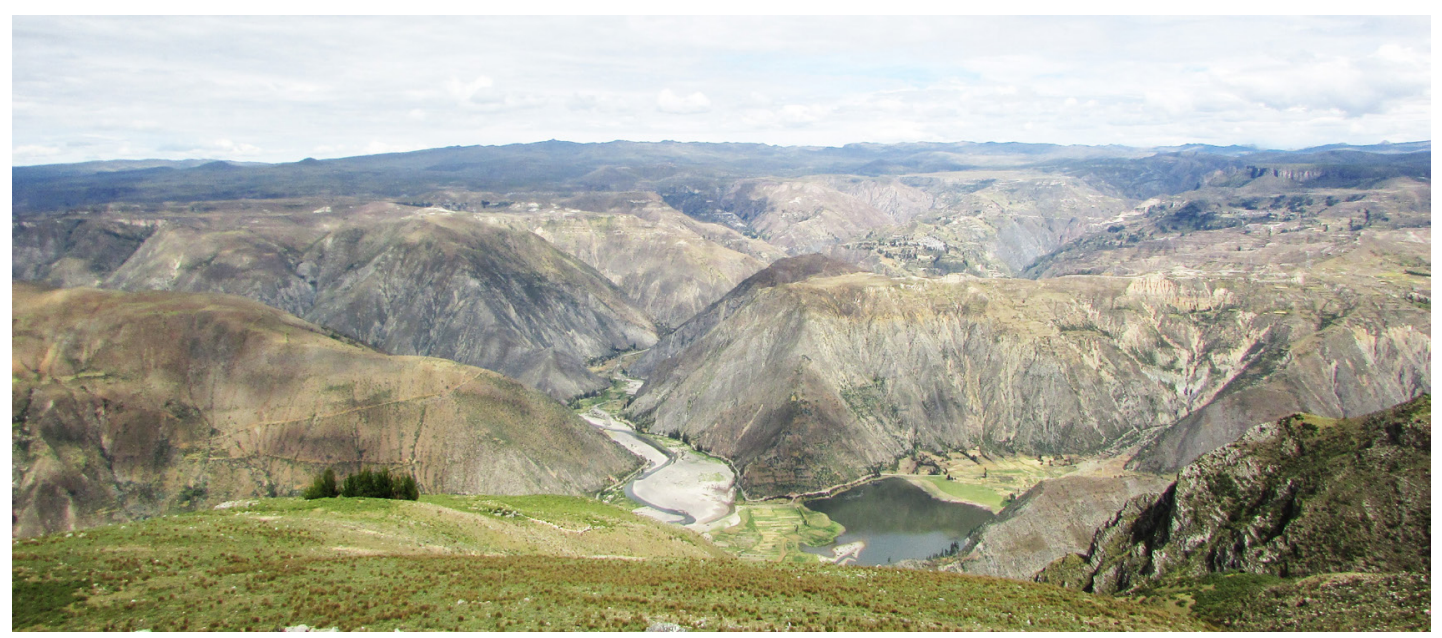

Figura 4. Relieve geográfico accidentado del curso alto del río Qaracha, vista desde el sitio arqueológico Naupallaqta. Foto de Juan Tello.

\section{RED DE POBLAMIENTO ALDEANO DEL ALTO QARACHA}

El alto Qaracha es un sistema de drenaje altoandino con quebradas de laderas pronunciadas e inclinadas entre los 3,000 y $4300 \mathrm{~m} \mathrm{s.} \mathrm{n.} \mathrm{m.,} \mathrm{que} \mathrm{casi} \mathrm{no} \mathrm{permite} \mathrm{un} \mathrm{espa-}$ cio adecuado para el desarrollo urbano. Las redes de poblados ocupan la cresta de la cadena montañosa que se eleva en ambas márgenes del río Qaracha ${ }^{5}$. La superficie de cima formaba el principal espacio de habitad humano, donde se desplazan los restos de una serie de poblados estructurados en núcleos habitables, aprestos en condiciones de un medio aldeano. La ocupación de este ambiente frecuentemente está asociada con redes viales, instalaciones hidráulicas y terrenos de cultivo con sistemas de andenería por sobre el piso del valle. Los asentamientos tardíos en esta zona están dispersos de acuerdo a su categoría sobre las partes altas, en laderas y piso de quebra$\mathrm{da}$, generalmente en macizos y promontorios naturales e intervisibles que divisan lo profundo hasta del valle.

5. Los sitios registrados en la exploración del alto Qaracha siguen el curso longitudinal sur-norte de este río, desde la meseta altoandina (puna) hasta la zona keswa del cañón profundo del valle. 


\section{Llaqta Pata}

El sitio arqueológico Llaqta Pata se ubica a 3,800 metros de altitud, el poblado ocupa la cima de un farallón elevado sobre una ladera escarpada de la margen derecha del río Urabamba, tributario del río Qaracha, cubre un área de 0.96 ha. El asentamiento muestra un rasgo aldeano con el núcleo habitable aislado por muros perimetrales aterrazados. El sitio está circundado por una fuerte pendiente vertical que brinda una protección natural, mientras tanto por el lado sur la topografía posee una fractura tectónica que dificulta el acceso al lugar. El acceso principal al sitio se realiza por una grieta de roca ubicado al lado norte del Sector I. Llaqta Pata se eleva en una falla geológica, dividido por una fractura central en dos sectores.

Sector I, se ubica al extremo nor-este, está delimitado por secciones de un muro periférico que genera un espacio habitable al interior. Las estructuras habitables son bastante rusticas de planta circular con un promedio de 5 a $6 \mathrm{~m}$ de diámetro, aparecen aislados y alrededor de un espacio central, formando conjuntos de grupo de patio. En la superficie aparecen abundante cantidad de fragmentos de obsidiana principalmente lascas, deshechos y restos de trabajo de este producto.

Sector II, se ubica al extremo sur-oeste, un muro perimetral rodea el sector por secciones, aunque no se distingue con claridad alguna ruta de circulación, el acceso al Sector II es salvando la línea de fractura del farallón que separa ambos sectores. Presenta edificios rústicos de planta circular que aparecen formando conjuntos alrededor de pequeños espacios irregulares, los elementos asociados son fragmentos de cerámica burda, abundantes lascas y restos de talla lítica de la obsidiana.

Este poblado luce rasgos aldeanos y responde al patrón generalizado de ocupación de zonas altas, condicionados a las restricciones de la geografía. Llaqta Pata está protegido de manera natural y cuenta con un solo ingreso, la cima del peñol es ligeramente plano delimitada por muros de contención que lo circundan, de tal modo que el poblado adquiere arreglos arquitectónicos en un espacio limitado. En ambos sectores, los edificios presentan una disposición similar, están distribuidos de manera aislada o formando conjuntos de grupo patio, aunque no se reconoce alguna ruta de circulación definida. Estos indicadores lo definen como un poblado de carácter espontáneo ${ }^{6}$, ocupado quizá de manera esporádica en un lugar estratégico. La ubicación de Llaqta Pata obedece a un repertorio de actividades económicas específicas, relacionado con la explotación de recursos minerales, desde este lugar se dominaba el curso bajo del río Urabamba, acceso directo desde a la fuente de obsidiana Quispisisa. La posición de Llaqta Pata adyacente a la cantera Quispisisa puede asociarse con la explotación y obtención de este mineral, esta corta distancia permitía el flujo

6. El carácter espontáneo de poblados altoandinos está relacionado con la eventual ocupación de sitios estratégicos en un contingente escenario de inestabilidad política (Canziani, 2009). 
de obsidiana a gran escala en el curso alto del Qaracha. El asentamiento sirvió como centro de producción lítico, las áreas de actividad estaban organizadas de acuerdo a las distintas fases de reducción lítica; los patios son áreas primarias donde debieron depositarse los nódulos y núcleos de obsidiana, posteriormente cada especialista ejecutaba el trabajo final en los edificios circulares.

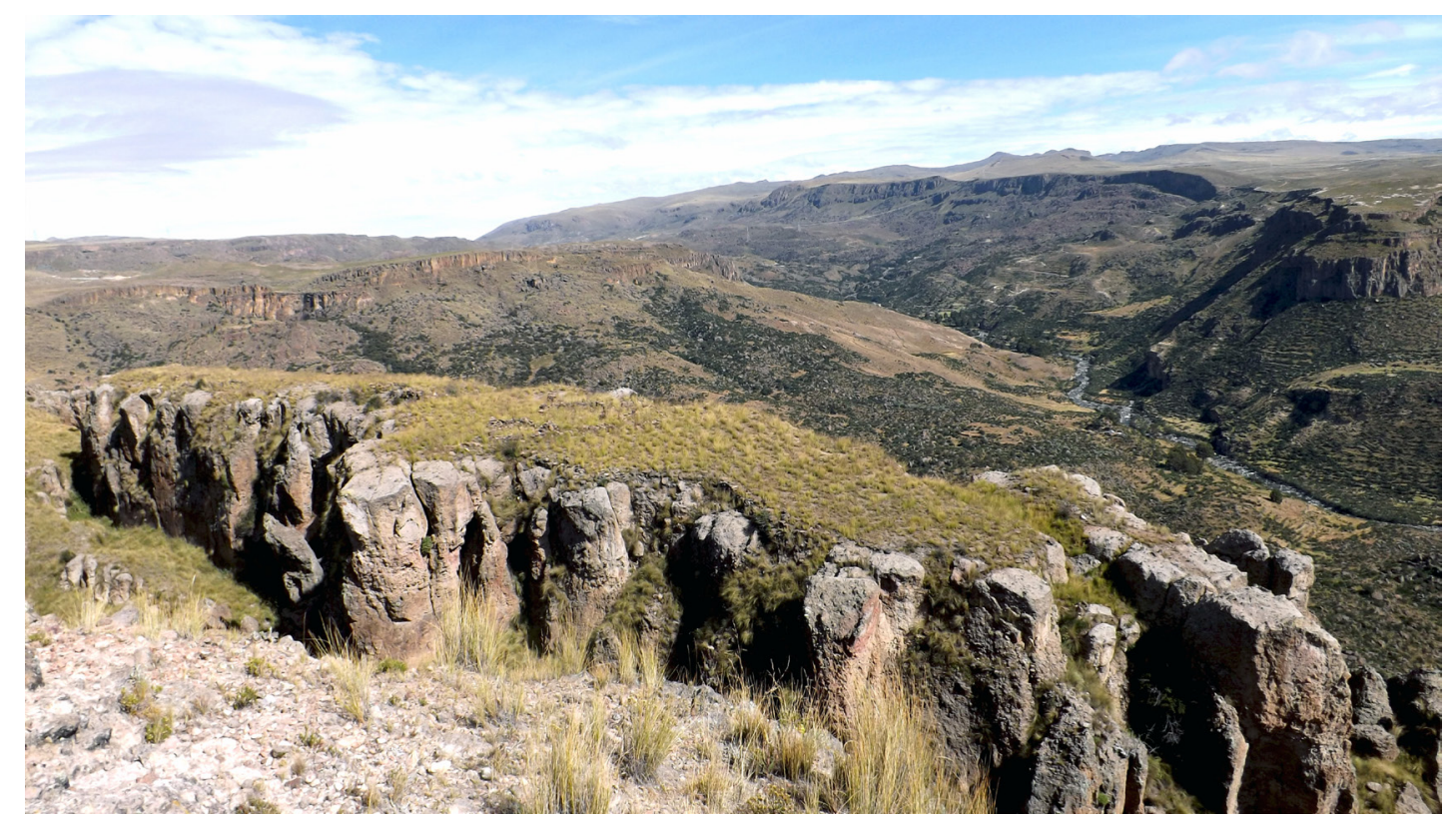

Figura 5. Vista panorámica del sitio arqueológico Llaqta Pata, en la cima de una falla geológica. Al fondo el curso alto del río Qaracha. Foto de Juan Tello.

\section{Marca Marca}

El sitio prehispánico Marca Marca ${ }^{7}$ se ubica a 3,550 metros de altitud, adyacente al pueblo actual de Colcabamba. Se eleva sobre un montículo escarpado de baja altitud en el piso de la quebrada Aywinto, tributario del río Qaracha. El sitio presenta un conjunto de construcciones circulares sobre una elevación natural, la visión desde el yacimiento domina la parte baja de la quebrada. Las estructuras habitables son bastante rústicas, sin aparente orden ni rutas de circulación, no es posible precisar por el estado ruinoso y por la espesa vegetación que cubre el lugar. El núcleo habitable es de 0.82 ha., está protegido por un muro alto que le brinda una protección por el lado oeste, la topografía agreste rodea el sitio que dificulta el acceso al lugar. En la superficie del sitio existe una sorprendente cantidad de lascas, deshechos y restos

7. Este sitio fue identificado recientemente por Contreras et al. (2012), como un centro importante de reducción lítica, cercano a la fuente de obsidiana Quispisisa. 
de talla lítica de la obsidiana, asociados con fragmentos de alfarería simple de pasta porosa y superficie áspera.

Las observaciones en Llaqta Pata han revelado la función principal del sitio como centro de producción lítico, un pueblo acondicionado en zona templada con una intensidad de ocupación para la adquisición y producción de artefactos líticos en uso activo durante este periodo. La materia prima obtenida en la cantera Quispisisa, se trasladaba en forma de nódulos selectos y en este lugar realizaban el proceso final de reducción y obtención final de artefactos de obsidiana, visible por la gran cantidad de lascas y deshechos que revelan la intensidad de esta producción a gran escala.

\section{Ituni}

El sitio Ituni se ubica a 3,670 metros de altitud, sobre una meseta elevada de la margen izquierda del río Qaracha, se extiende sobre un área de 15 ha. Se trata de un poblado instalado sobre una ladera de topografía abrupta que le brinda una protección natural. El núcleo urbano se encuentra en un espacio estratégico sobre el límite superior keswa, el ascenso es dificultoso y la visión desde el sitio domina el curso alto del Qaracha. El sitio está naturalmente bien protegido con adaptaciones rurales de terrazas intercaladas y conjuntos de edificios circulares edificados sobre una nivelación rudimentaria, en las pendientes y cumbres de los cerros. La superficie

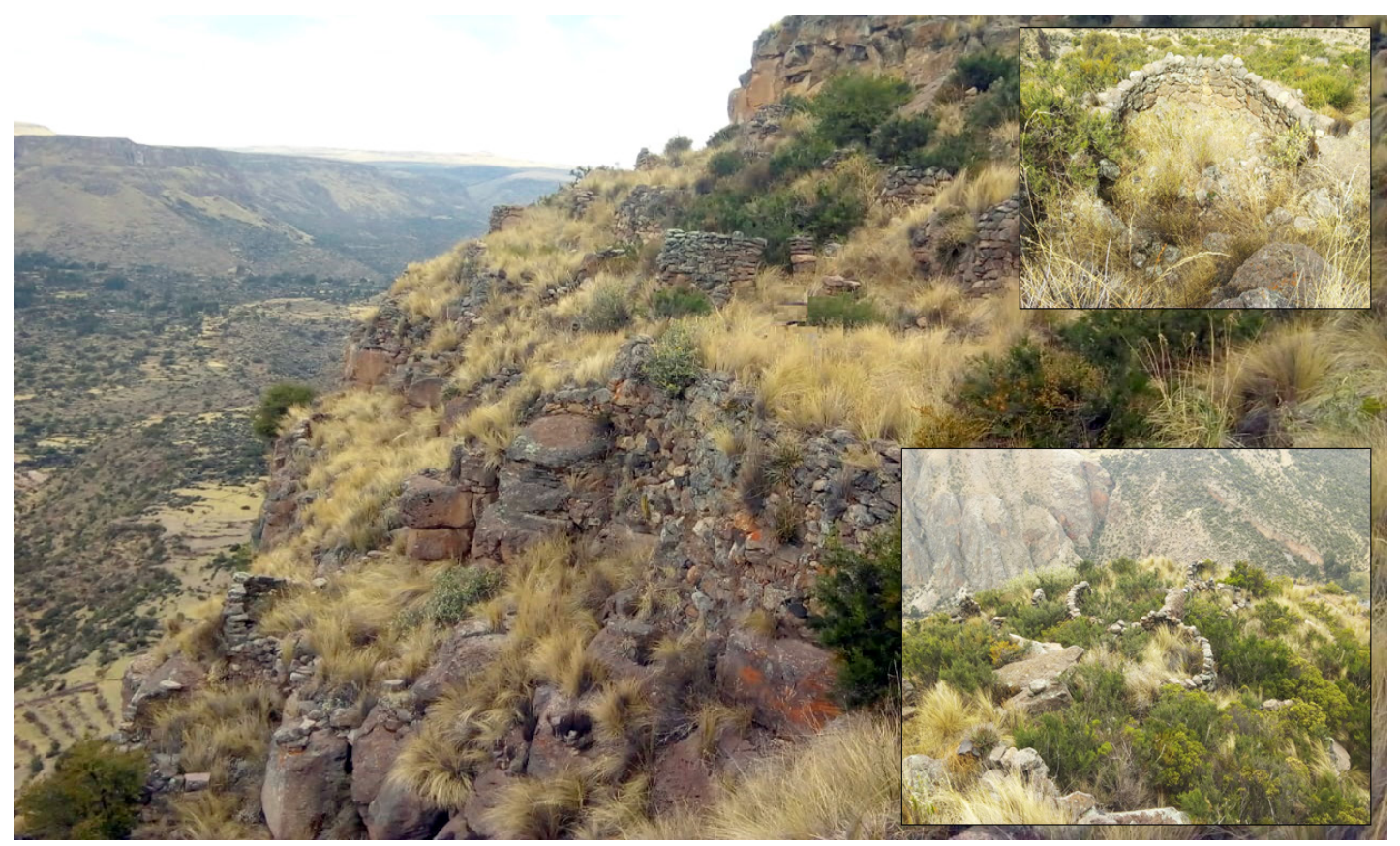

Figura 6. Vista panorámica del sitio Ituni con nivelación de terrazas sobre una quebrada empinada. Al fondo el curso alto del río Qaracha. Foto de Juan Tello. 
del terreno presenta escarpas de falla a lo largo de la meseta, sobre las paredes laterales existen cavidades funerarias revestidos de pirca con pequeños vanos de acceso, son estructuras funerarias múltiples con restos humanos disturbados al interior. Se encuentra fragmentos de cerámica burda en gran cantidad y lascas de obsidiana de buena factura.

\section{Wiska Ranra}

El sitio arqueológico Wiska Ranra se ubica a 3,290 metros de altitud, sobre un accidente topográfico definido como escarpa de falla en la quebrada lateral de la margen derecha del río Qaracha, en un área de 5.44 ha. El terreno es abrupto de pendiente inclinado con rocas fracturadas por una evidente erosión glacial que deslizó el terreno en un pasado remoto, anterior a la fundación del asentamiento. El sitio presenta una serie de terrazas artificiales formados entre las salientes de rocas angulosas; las estructuras habitables se erigen sobre esta nivelación rudimentaria, son rústicas, de forma circular y elaborados con material del lugar. La visión desde el sitio domina la parte baja del río Qaracha y permite el acceso a este recurso hídrico y a la zona cultivable en el piso del valle. El sitio está naturalmente protegido por este accidente topográfico que dificulta el acceso al lugar por todos los puntos cardinales. En la superficie aparece una gran cantidad de cerámica burda y reducidas lascas de obsidiana.

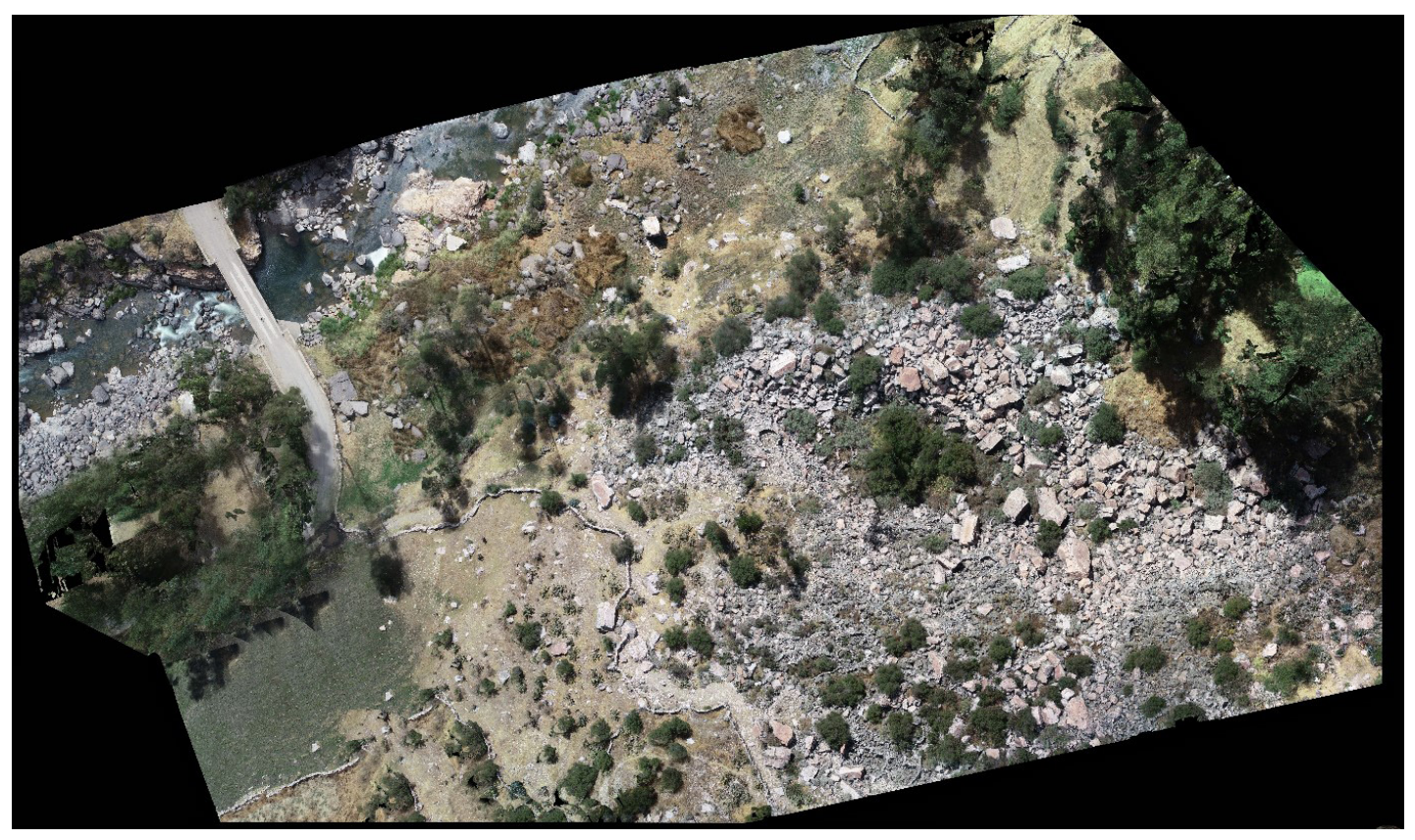

Figura 7. Fotogrametría del sitio Wiska Ranra. Fue emplazado sobre el piso de valle y laderas del río Qaracha. Elaborado por Juan Tello. 


\section{Saqsamarca}

El sitio arqueológico Saqsamarca ${ }^{8}$ se asienta a 3,370 metros de altitud, a 700 metros al norte del distrito homónimo Sacsamarca, se encuentra sobre el triángulo elevado formado por los ríos Huanca Chaca y Qaracha, abarca un área de 2.17 ha. El acceso principal al sitio se realiza por un camino labrado ubicado al lado sur del yacimiento. El poblado se encuentra sobre un macizo rocoso de laderas escarpadas que han sido remozados con muros perimetrales y aterrazamiento gradual. El núcleo habitable abarca la cima del montículo, los restos de arquitectura están mal conservadas para estimar su proporción, pero tenía viviendas predominantemente circulares. El sitio está protegido de manera natural por una pendiente vertical que alcanzan el piso de la quebrada por donde discurren los ríos mencionados, el camino principal ha sido labrado por el flanco izquierdo del macizo y alcanza el piso del valle que se extiende sobre el río Qaracha, al lado norte del sitio.

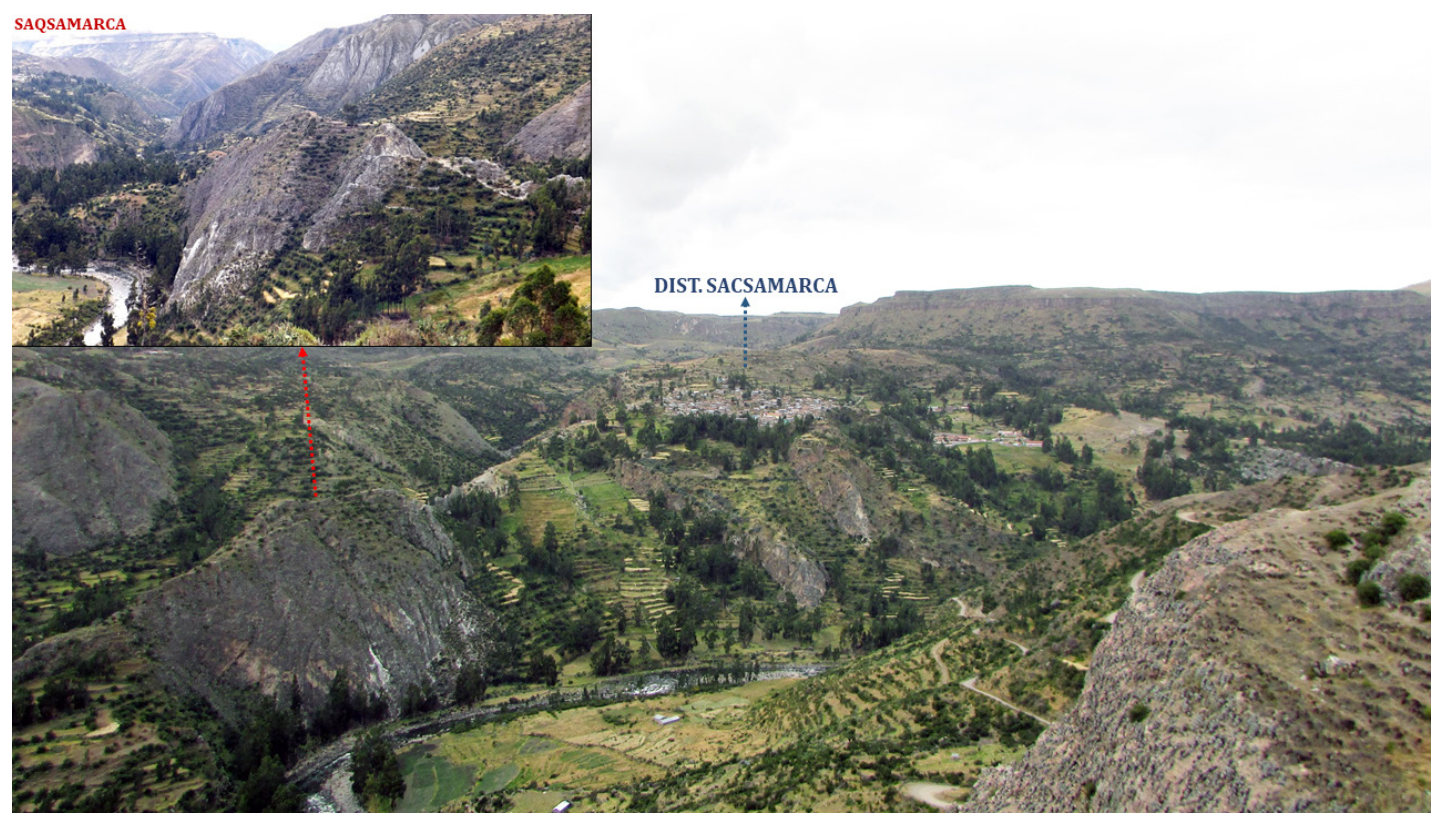

Figura 8. Vista panorámica del sitio arqueológico Saqsamarca, sobre un cono macizo de roca. Este sitio pudo ser asiento de colonos mitmaq durante la ocupación Inca del Qaracha. El curato Sacsamarca (Siglo XVI), actual distrito Sacsamarca, se instaló cerca de este sitio. Foto de Juan Tello.

8. Este sitio pudo haber sido una aldea que fue repoblada con colonos mitmaq durante la ocupación Inca del Qaracha. El pueblo de reducción Toledana Sacsamarca se colocó cerca de este sitio, a 700 metros de distancia. De acuerdo a Pedro de Carbajal, corregidor de Vilcas Huamán: “[...] En tiempo de su gentilidad, fueron subjetos a solos sus caciques y principales, hasta que los Ingas se enseñorearon dellos [...]. Los Ingas los subjetaron y gobernaron con mayor tiranía" (1881, p. 148-149). Durante el Tawantinsuyo esta región fue repoblada por mitimaes, entre los que figuran huancas, xauxas (Huertas, 1979) y quillasacsamarcas (Urrutia, 2014). 


\section{Tarunka}

El yacimiento arqueológico Tarunka se levanta a 3,470 metros de altitud, a 1 kilómetro de distancia al sur del distrito de Sancos, se erige sobre una meseta elevada erosionada constantemente por la quebrada Tarunka, afluente izquierdo del río Qaracha. Es un poblado extenso de 11.02 ha emplazado en la cima de la meseta que contiene una densa concentración de estructuras circulares rústicas, aparecen aisladas y formando conjuntos de grupo patio. Por el lado norte y oeste del sitio, fluye el río homónimo que ha formado una profunda quebrada de paredes verticales que le impone un límite fisiográfico y le brinda una protección natural; el lado sur está protegido por un muro alto, el sitio está encerrado por el lado este con un muro perimétrico de apariencia aterrazada. El poblado Tarunka es intervisible con el asentamiento Qochamarca instalado en la misma altitud, hacia el levante del río Qaracha. En la superficie se encuentra fragmentos de cerámica simple en gran cantidad y reducidas lascas de obsidiana.

\section{Qochamarca}

El asentamiento Qochamarca es un núcleo habitable extenso, abarca un área de 20.70 ha se ubica a 3,715 metros de altitud, se encuentra en la margen derecha del río Qaracha emplazado sobre unos montículos naturales que se elevan al borde de una meseta elevada sobre una quebrada profunda que se levanta desde el río Qaracha y le brinda una protección natural. El núcleo urbano se encuentra distribuido en un espacio estratégico al límite superior keswa por su vista excepcional de la quebrada. El acceso al sitio se realiza por un fragoso camino que asciende la quebrada desde el río Qaracha, aunque el acceso natural proviene del lado sur cortando la planicie que lo rodea. El asentamiento muestra un rasgo aldeano con acondicionamientos arquitectónicos distintos que aíslan las estructuras en dos grandes núcleos habitables:

Sector I, está formado por dos promontorios naturales rodeados por muros perimetrales que lo delimitan generando un espacio habitable interno, sus laderas han sido remozados con terrazas superpuestas que sostienen los edificios rústicos de forma circular. En la hendidura de ambos promontorios los recintos están agrupados en unidades de grupo patio; hacia un lado aparece una estructura rectangular de gran dimensión con divisiones internas que podría ser un tampu inca. En la superficie aparece gran cantidad de fragmentos de cerámica burda, artefactos líticos y obsidiana.

Sector II, abarca la meseta ondulada en la que se encuentra un vasto núcleo habitable emplazado sobre una hendidura al pie de un espolón rocoso. Los edificios de planta circular son de mayor tamaño y mejor elaborados con vanos de roca empotrada y paredes de apariencia careada formados por hiladas de roca angulosa, algunos recintos están ligeramente coloreados con arcilla rojiza en la parte interna. Los elementos asociados son fragmentos de cerámica burda, lascas 
de obsidiana y abundantes artefactos líticos entre morteros fragmentados y batanes incompletos.

Qochamarca es un asentamiento protegido de manera natural con acceso abierto que le da paso a la variedad ecológica del lugar, En ambos sectores, los edificios circulares presentan notables variantes en sus disposiciones. El Sector I tiene arreglos de terrazas escalonadas que rodean los promontorios naturales; en el Sector II, sobre las hendiduras de la planicie se concentra el núcleo habitable principal. En ambos sectores, los edificios forman conjuntos de vivienda en un aparente ordenamiento de grupo patio, esta disposición aparenta similitud con la unidad alveolar definida para territorio asto ${ }^{9}$. El rasgo topográfico más visible del sector es un espolón granítico de altura considerable, el material que se desprende por la erosión ha sido utilizado como elemento constructivo de los edificios. Las paredes escarpadas del espolón contienen cavidades funerarias finamente labrados que intruyen la roca y orlados con voladizos de lajas, se encuentran equidistantes por toda la pared del farallón a una gran altura y con difícil acceso. Sobre la planicie se encuentran recintos grandes formados con hileras de piedras empotradas de gran dimensión que se atribuye a las grandes estancias pastoriles por lo que deben corresponder a corrales prehispánicos.

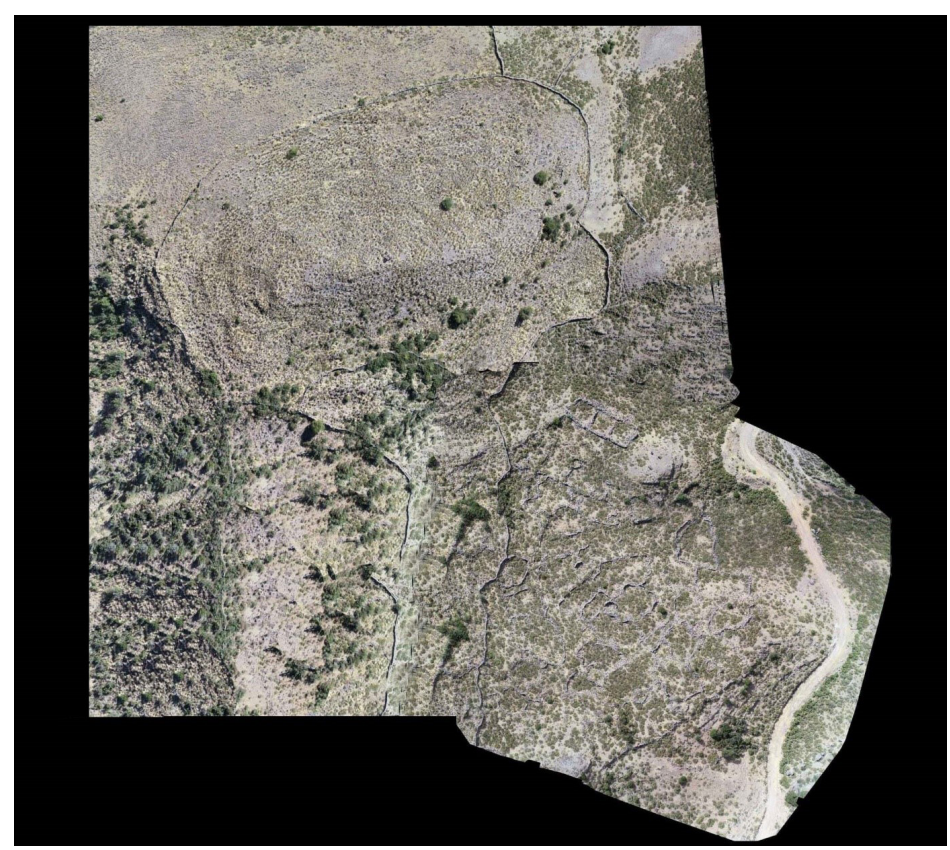

Figura. 09. Fotogrametría del sitio Qochamarca. El sector I contiene una estructura rectangular con divisiones internas que podría ser un tampu inca. Elaborado por Juan Tello.

9. De acuerdo a Lavallée y Julien (1983), el elemento básico de construcción del patrón de asentamiento asto, es la unidad alveolar, se trata de un conjunto de edificios circulares de tamaño variable agrupados alrededor de un patio central, que podrían constituir una vivienda familiar con depósitos y áreas de actividad. 


\section{Ñaupallaqta}

Ñaupallaqta está ubicado en el tope cónico de una montaña que se eleva en la margen derecha del río Qaracha a 4,080 metros de altitud. El núcleo urbano se concentra en la cresta de esta elevación ocupando un área de 29.71 ha, el lado norte del sitio es inaccesible y le brinda una protección natural, mientras que el lado sur es una ladera aterrazada que alcanza la cresta de montaña, entre las terrazas se ha podido identificar accesos a manera de rampas que conducen de un nivel a otro, cada nivel contiene regularmente dos edificios equidistantes con un espacio central a modo de patio, todo parece indicar que estos recintos cumplían funciones habitacionales y los espacios áreas de trabajo. Las estructuras circulares son de buena factura, construidas en doble hilada con lajas y piedras del lugar. En la cima de la colina se encuentra una serie de plazas circulares de enormes dimensiones a distintos niveles, los cuales han sido reforzados con enormes muros de contención adaptados perfectamente a la topografía. En la superficie aparecen fragmentos de utillería simple, abundantes artefactos de piedra, morteros fragmentados y lascas reducidas de obsidiana.

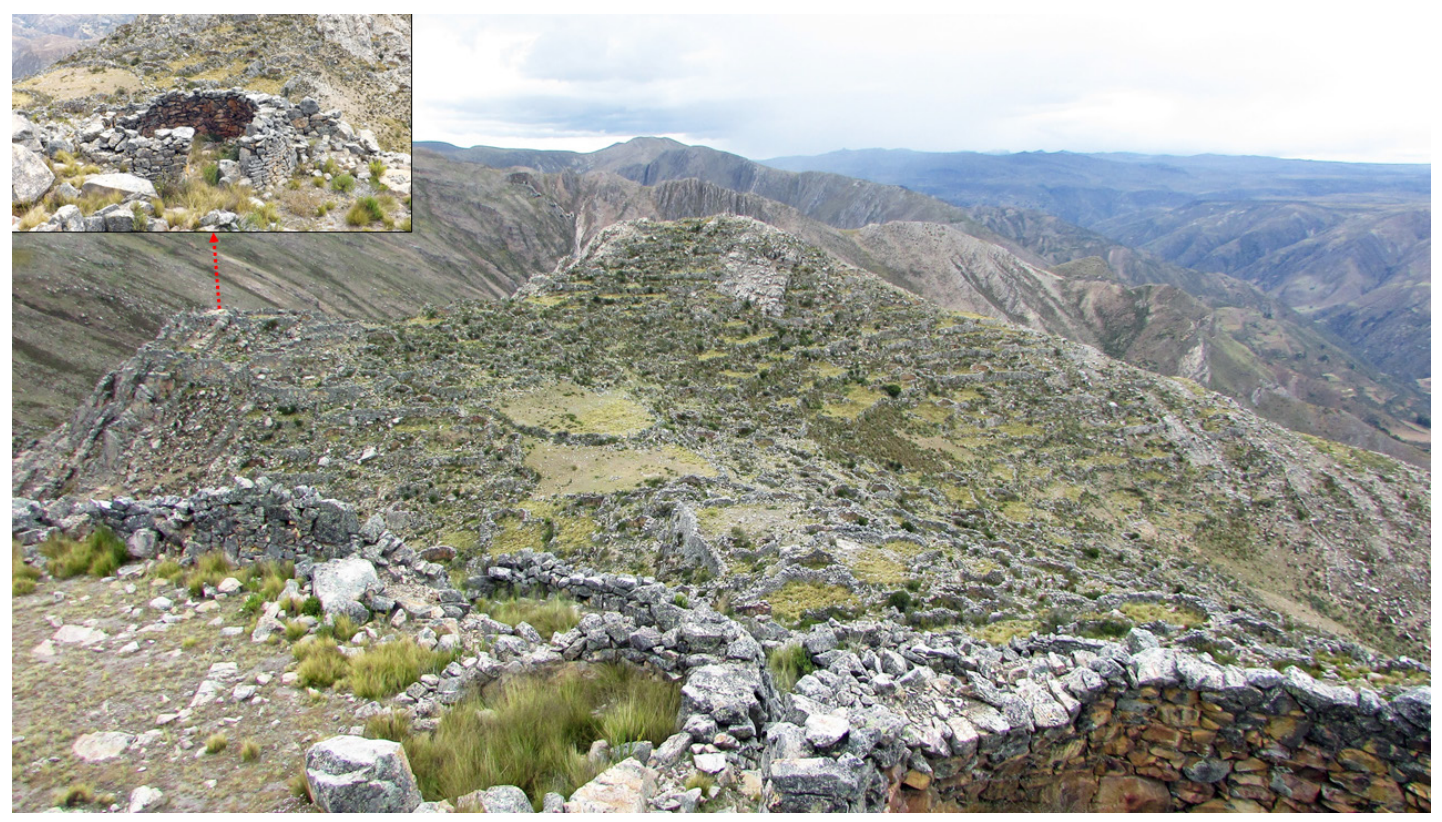

Figura 10. Vista panorámica del sitio Naupallaqta, en el tope cónico de una montaña. Foto de Juan Tello. 


\section{Pukara}

El sitio Pukara ${ }^{10}$ se eleva a 3,890 metros de altitud, está ubicado en la cima de un farallón que se levanta sobre una montaña formado por los ríos Lucanamarca y Qaracha. La ubicación de Pukará en un lugar estratégico se relaciona con su naturaleza defensiva y el control de los diferentes pisos ecológicos, su posición dominaba el territorio circundante en proximidad a la zona agrícola al pie del río Qaracha e integrado por la actividad pastoril sobre el piso keswa. El núcleo urbano de Pucará es extenso abarca un área total de 71.92 ha, en él se ha registrado un número considerable de viviendas, muro defensivo, accesos, terrazas y sistemas de almacenamiento hídrico.

La ocupación prehispánica se extiende sobre tres picos montañosos que fueron utilizados como una fortaleza natural de carácter defensivo:

Sector I, siendo un peñón una elevación natural, en la cima se observa estructuras circulares y al centro aparece una plaza rectangular rodeado de kallankas de factura inca ${ }^{11}$. Se distingue un sistema de almacenamiento hidráulico con pozos y canales labrados en la roca, el sector presenta un acceso restringido por el lado sur-oeste del peñón.

Sector II, es un peñón natural en la cima se observa estructuras circulares y restos de estructuras cuadrangulares, el sector presenta un acceso restringido con escalinatas al lado sur-oeste del peñón.

Sector III, formado por un peñón natural, en la cima se observa un núcleo urbano extenso de estructuras circulares adaptadas a las restricciones del terreno, aparecen concatenadas sin aparente orden, el sector presenta un acceso con escalinatas tallados en la roca, al lado sur-oeste.

Las características geomorfológicas de naturaleza defensiva del sitio Pukará determinaron que sus pobladores utilizaran un sistema de patrón constructivo disímil de acuerdo a los periodos de ocupación rukana e inka; las construcciones son circulares y rectangulares, muy bien adaptadas a la topografía con materiales típicos de la zona. Pukará tiene el mayor número de edificios de cualquier sitio en el área muestreada, en términos de restos arquitectónicos presentes constituye el sitio más densamente cubierto. Las estructuras circulares medidos varían en diámetros de 5

10. Pukará fue identificado inicialmente por Valdez y Vivanco (1994). Posteriormente, Vivanco (2003) lo define como una fortaleza natural, esta categoría también se ve confirmada por Meddens (2005, p. 90): "Se encuentran allí estructuras circulares y rectangulares, patios y muros de defensa".

11. En Pukará se logró identificar material cerámico del Horizonte Tardío. En el sector I, aparecen fragmentos de cántaros asociados a las kallankas, una de las formas comunes fabricados en Pukará durante la ocupación inca. 
a 6 m la mampostería consiste en piedra de campo clasificada y colocada en cursos aleatorios de hiladas superpuestas, se usa mortero de lodo. Los edificios rectangulares parecen haber sido formadas con piedras seleccionadas de forma rectangular, con una técnica de muro seco que se ha aplicado en general, pero solo en raras ocasiones, los lados interiores de las paredes tienden a terminarse llenando los espacios con tierra y piedras pequeñas.

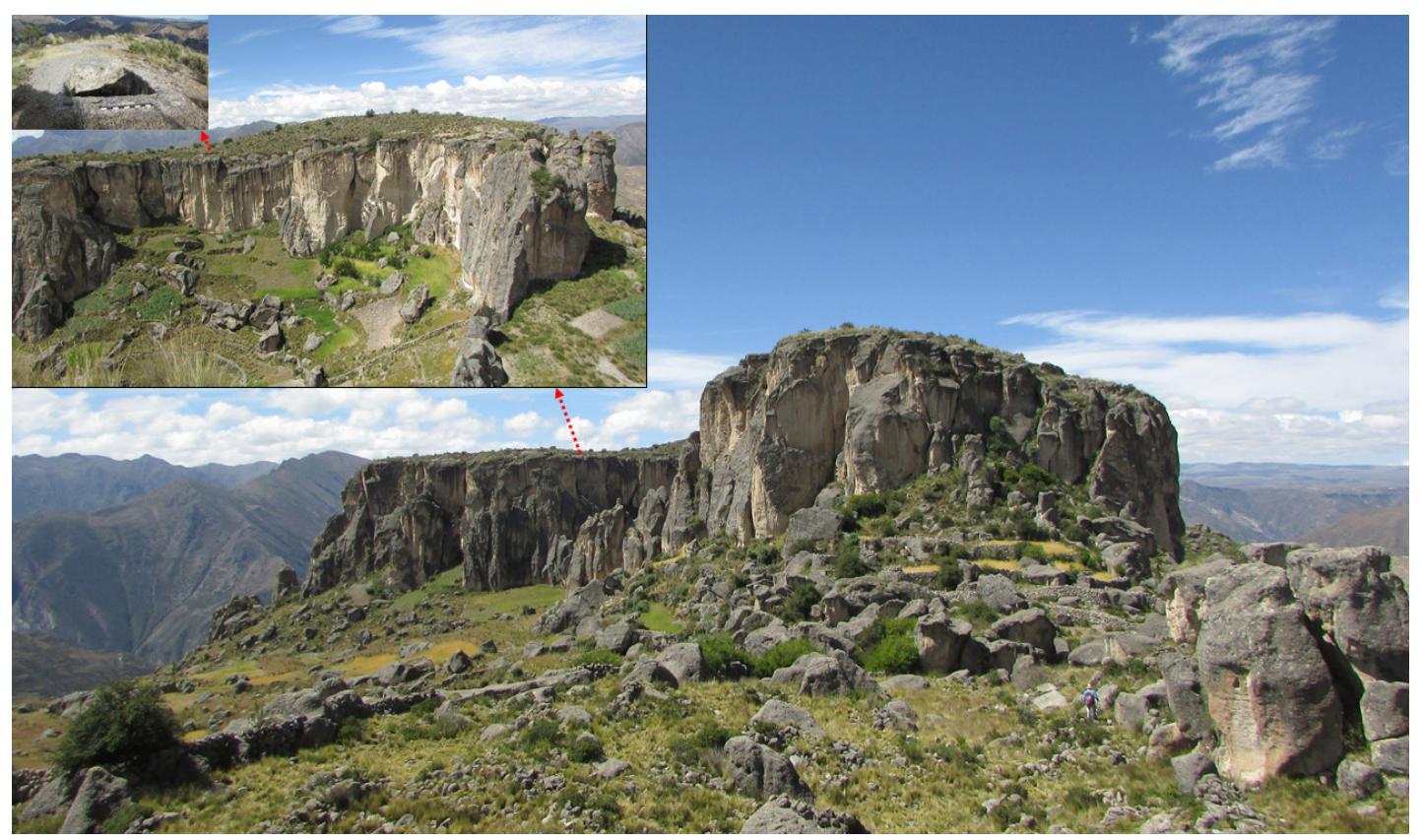

Figura 11. Vista panorámica de la fortaleza de Pukará. El sector I, contiene edificios de factura inca y sistemas de almacenamiento hidráulico. Foto de Juan Tello.

\section{ZONAS DE VIDA Y MEDIO ECOLÓGICO PREHISPÁNICO}

En el alto Qaracha podemos encontrar diferentes zonas de vida ${ }^{12}$ que se yuxtaponen con las unidades geológicas reconocidas del lugar. Estas zonas permutan a lo largo del curso longitudinal del Qaracha, de acuerdo a su medio ecológico se reparten en tres franjas ecológicas: Paramo húmedo Subalpino Subtropical (altiplanicies), Bosque húmedo Montano Subtropical (mesetas disectadas) y Bosque seco Montano Bajo

12. El ecosistema del alto Qaracha presenta marcados contrastes de zonas de vida de geografía difícil y fragoso tránsito, ergo la sorprendente biodiversidad altoandina diseminados en franjas ecológicas por el súbito cambio altitudinal que forma el dren alto del río Qaracha (ONERN, 1976; INRENA,1995). 


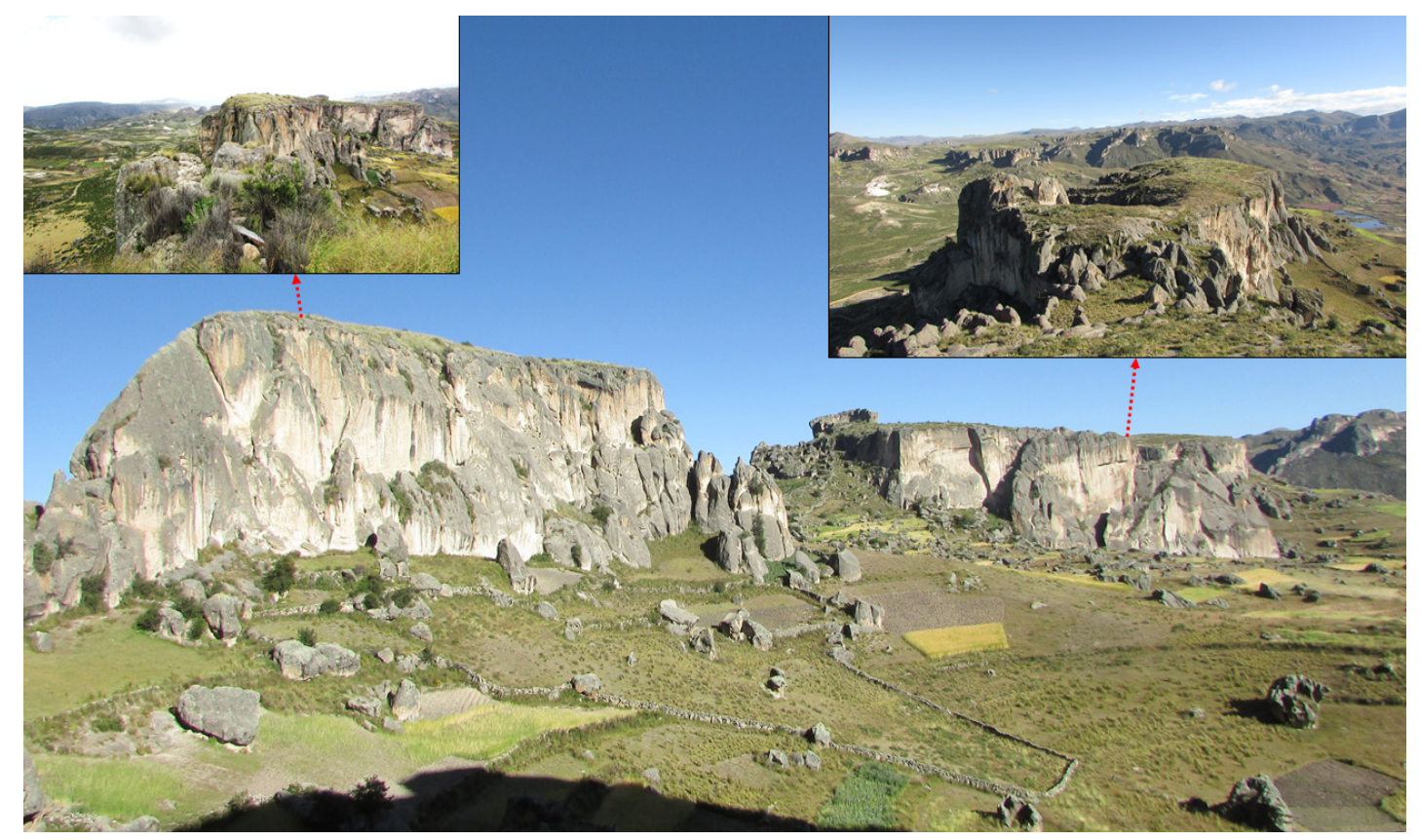

Figura 12. Vista panorámica de la fortaleza de Pukará. El sector II (izquierda), contiene estructuras rectangulares. El sector III (derecha), es un vasto núcleo habitable PIT. Foto de Juan Tello.

Subtropical (valles interandinos). Este espacio altoandino incluye tres de las ocho regiones naturales establecidos por Pulgar Vidal (1996): keswa (valles y quebradas $2.400-3.500 \mathrm{~m} \mathrm{~s}$. n. m.), suni (mesetas y cadenas escarpadas $3.500-4.000 \mathrm{~m} \mathrm{s.} \mathrm{n.} \mathrm{m.)}$ y puna (altiplanicie $4.000-4.800 \mathrm{~m} \mathrm{~s}$. n. m.). En cada franja ecológica se despliega un medio biótico conformado por una variedad de recursos naturales que se despliegan en un espectro vertical que fueron aprovechados adecuadamente por los hombres de la época prehispánica tardía. Los pueblos del alto Qaracha fueron instalados sobre puntos estratégicos que dan paso al variado abanico ecológico y facilitan la explotación de los recursos naturales. Estos pueblos fueron desplegados en sitios específicos, de acuerdo al uso natural de cada zona ecológica. Esta distribución de los sitios sobre cursos de agua, quebradas productivas y áreas pastoriles no puede ser sino la imagen de un territorio aldeano acondicionado a un medio de vida rural.

Páramo húmedo Subalpino Subtropical (altiplanicie), esta franja corresponde a la meseta altiplánica, zona esteparia de escorrentía constante debido a las ciénagas y los glaciales que se originan en los conos volcánicos. Es un área favorable para la actividad pastoril y explotación de recursos minerales, principalmente se obtenía la obsidiana Quispisisa de la fuente Jiccha Parcco. Llaqta Pata, el poblado más austral del área de estudio está a $10 \mathrm{~km}$ río abajo de esta cantera, esta corta distancia puede asociarse 


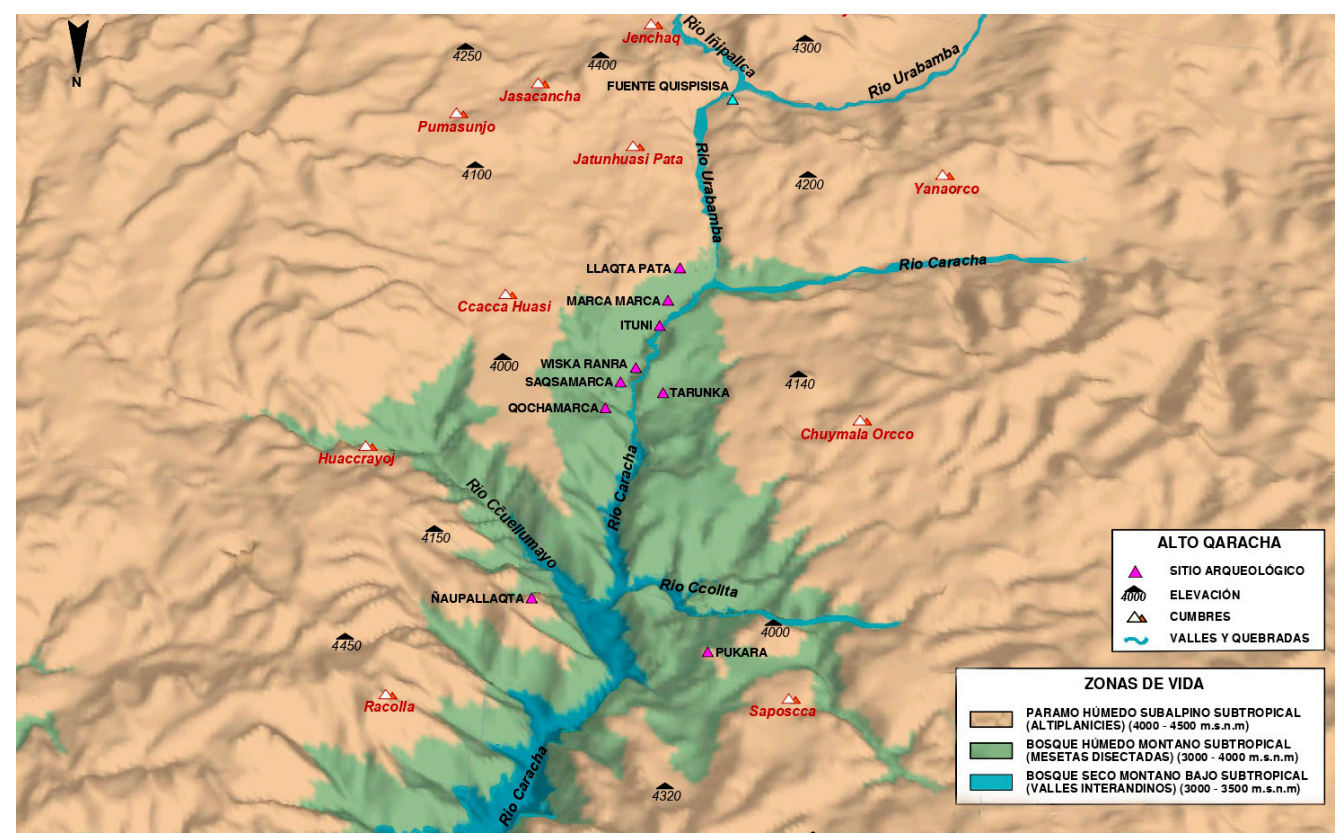

Figura 13. Distribución de los poblados prehispánicos en las zonas de vida del alto Qaracha. (Elaborado por Marco Taquiri).

Tabla 01. Distribución de los poblados prehispánicos en las zonas de vida del alto Qaracha. (Elaborado por Marco Taquiri).

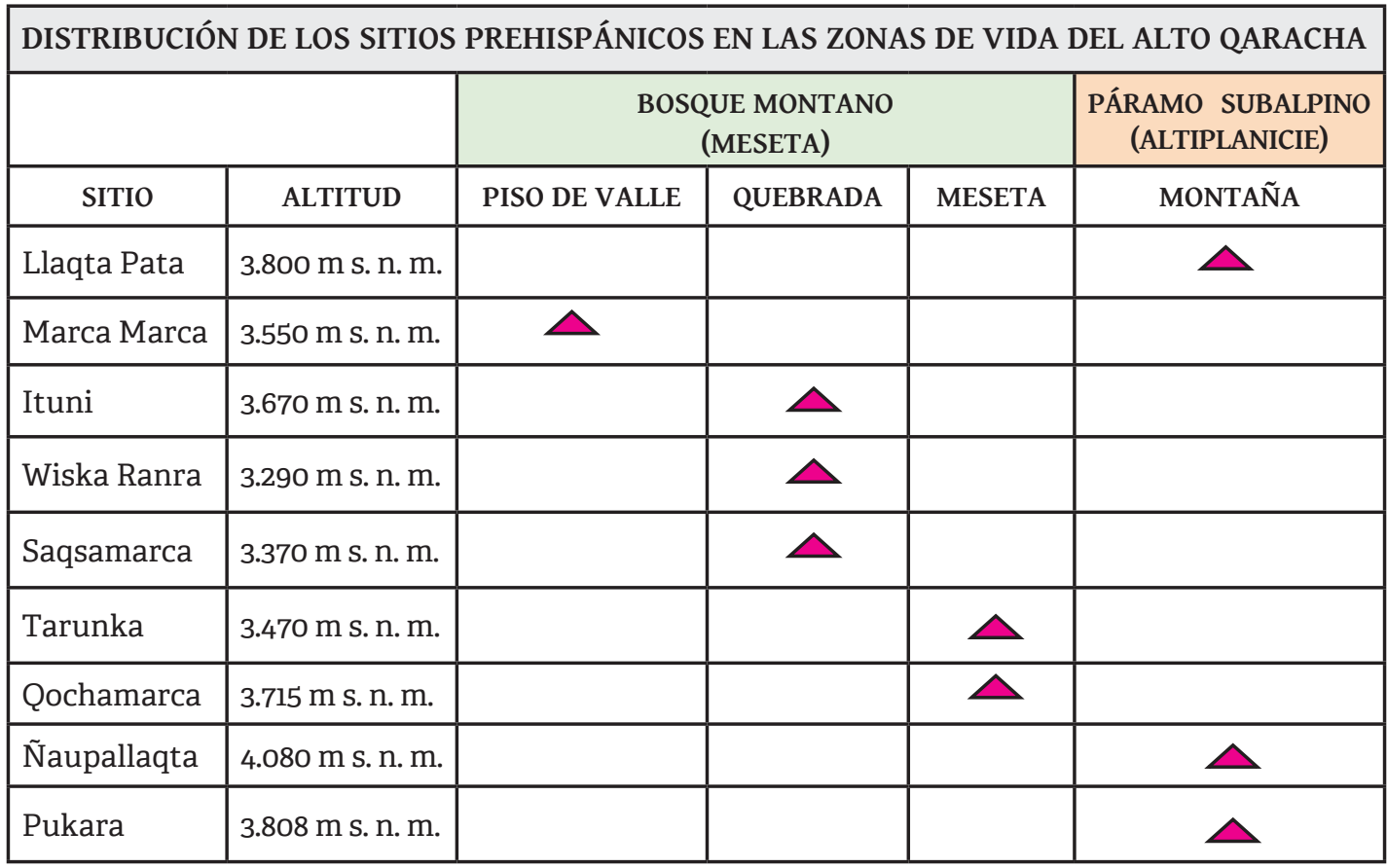


con la explotación y obtención de materia prima, que permitía el flujo de obsidiana a gran escala en la cuenca del río Qaracha. Pukará el poblado mas septentrional, fue un sitio de refugio natural que podía ser utilizado por todos los pueblos del Qaracha en tiempos de conflicto, este sería el mismo sitio al que huyeron los Soras después de su derrota con los incas ${ }^{13}$. Las percepciones son que Pukará estaba funcionando como un centro importante después de la conquista inca del área. Esto es sugerido por la arquitectura, que parece ser derivada de la planeación y diseño del Horizonte Tardío.

Bosque húmedo Montano Subtropical (mesetas disectadas), esta franja corresponde a los contrafuertes y mesetas que se elevan sobre el cauce del río Qaracha e incluye sus tributarios laterales. La mayor parte de los pueblos tardíos se despliegan en esta zona de vida, debido a la excelente visibilidad del entorno y las adecuadas condiciones climáticas que favorece el uso constante del suelo para la productividad agrícola. Generalmente la quebrada desciende con rápido declive y predomina la vegetación arbustiva. En las paredes laterales del Qaracha se despliegan terrazas agrícolas y sementeras qua ascienden del pie del río hasta la cima de las mesetas, vestigios sin duda de la alta productividad de esta zona.

Bosque seco Montano Bajo Subtropical (valles interandinos), esta zona de vida se extiende al pie del río Qaracha, es una reducida franja ecológica que se despliega en el septentrión del área de estudio, de relieve encañonado con riberas escabrosas y reducida área favorable para el cultivo, el lugar es impropio para subsistir. Aunque no se ha identificado ningún asentamiento sobre esta franja, es un área ideal para los sembríos en sementeras y el cultivo de productos cálidos.

\section{DISCUSIÓN}

Los tratados sobre territorialidad prehispánica en el área andina han permitido examinar en diversas escalas las dinámicas espaciales a través del estudio de los patrones de asentamiento que evidencian una fragmentación política sin precedentes para la época en cuestión, esta evidente segmentación está asociada a la aparición de grupos étnicos establecidos en regiones específicas con presencia de asentamientos fortificados que evidencian un periodo de conflicto endémico (Bauer et al., 2013;

\footnotetext{
13. Tal como lo describe Cieza de León, sobre la incursión de los generales de Pachacútec al territorio de los soras: "El rey salió de allí y anduvo hasta la provincia de Andaguaylas, a donde le fue hecho solemne recebimiento y estuvo allí algunos días, determinando si iría a conquistar a los naturales de Guamanga, o Xauxa, o los Soras y Rucanas; mas después de haber pensándolo, con acuerdo de los suyos determinó de ir a los Soras. Y saliendo de allí, anduvo por un despoblado que iba a salir a los Soras, los cuales supieron su venida y se juntaron para se defender. Había enviado Inga Yupangue capitanes con gente por otras partes muchas a que allegasen las gentes a su servicio con la más blandura que pudiesen y a los soras envió mensajeros sobre que no tomasen armas contra él, prometiendo de los tener en mucho sin les hacer agravio ni daño; mas no quisieron paz con servidumbre sino guerrear por no perder la libertad" (1880, p. 178).
} 
Canziani, 2009; D’altroy, 2015; D'altroy y Hastorf, 2002; Earle et al., 1987, 1988; Hastorf et al., 1989; Lumbreras, 1959, 1974; Matos 1959, 1966; Matos y Parsons, 1979; Parsons et al., 2000; Saintenoy, 2016). El grado de planificación de los asentamientos es variable según las condiciones del medio físico, la textura urbana toma arreglos arquitectónicos a una escala doméstica, los núcleos poblacionales se distinguen por su tamaño y la alta densidad de estructuras, existen pocas diferencias en cuanto a la forma y función de las construcciones (Lavallée y Julien, 1983). Este periodo experimentó un crecimiento demográfico general en los Andes Centrales, configurándose un territorio densamente poblado con la ocupación humana de todas las facetas ecológicas (Vega Centeno, 2017). En el alto Qaracha, esta proliferación se pone de manifiesto por la profusión de los poblados hacia zonas de altura por encima de los valles cultivables.

Sobre el poblamiento prehispánico en Ayacucho se ha propuesto que para este periodo se percibe un marcado patrón aldeano en un amplio entorno que en una etapa anterior formó el centro de desarrollo del imperio wari ${ }^{14}$. Esta recurrencia responde a los profundos cambios en el hábitat andino, las aldeas en el piso del valle fueron abandonados para dar lugar a nuevos poblados que ocupan la parte alta de la cadena de montañas. Las evidencias arqueológicas sugieren que para este periodo todos los asentamientos habían sido construidos en lugares estratégicos y dentro de un espacio territorial que permitía la práctica de la actividad agropastoril. La intervisibilidad jugó un rol importante como estrategia de ocupación de sitios defensivos, preferentemente la cima de las montañas, tal como indica Arkush, el dominio visual se proyectaba al entorno: "La visibilidad fue importante para decidir donde se construían. Los contactos visuales entre pukaras fueron importantes y no solo una consecuencia accidental de su ubicación en las cumbres" (2012, p. 311). Después del colapso de wari, existe la presencia de una variedad de grupos étnicos, con áreas de desarrollo afines a valles específicos. El río Pampas y sus afluentes fueron ocupados por los chocorbos y tanquiguas (Huertas et al., 1976). En el valle del río Chicha - Soras aparecen los Soras (Monzón, 1881a); en Lucanas y la cordillera occidental, los hatun rukanas (Monzón, 1881b); en el valle de Sondondo, los andamarcas (Monzón, 1881c); se considera el alto Qaracha como un territorio agregado a los rukanas de la parcialidad antamarca. Tradicionalmente se consideraba que estos grupos estaban incorpo-

14. Schreiber (1991), plantea que el centro administrativo wari de Jincamocco fue despoblado al final de la época 2B del Horizonte Medio y ocurre una regresión de aldeas hacia las partes altas del valle de Sondondo; Isbell (1970) propone que al final del Horizonte Medio 2B los asentamientos post-wari del valle de San Miguel fueron edificados en las partes altas; González Carré (en Huertas et al., 1976) ha reconocido poblados chocorbos cimeros en el curso superior del río Pampas; Valdez y Vivanco (1994) en el curso medio del río Pampas identificaron poblados post wari que ocupan lugares estratégicos; Vivanco $(1998,2003,2005,2013)$ identifica sitios naturalmente defensivos en el curso bajo del río Qaracha. 

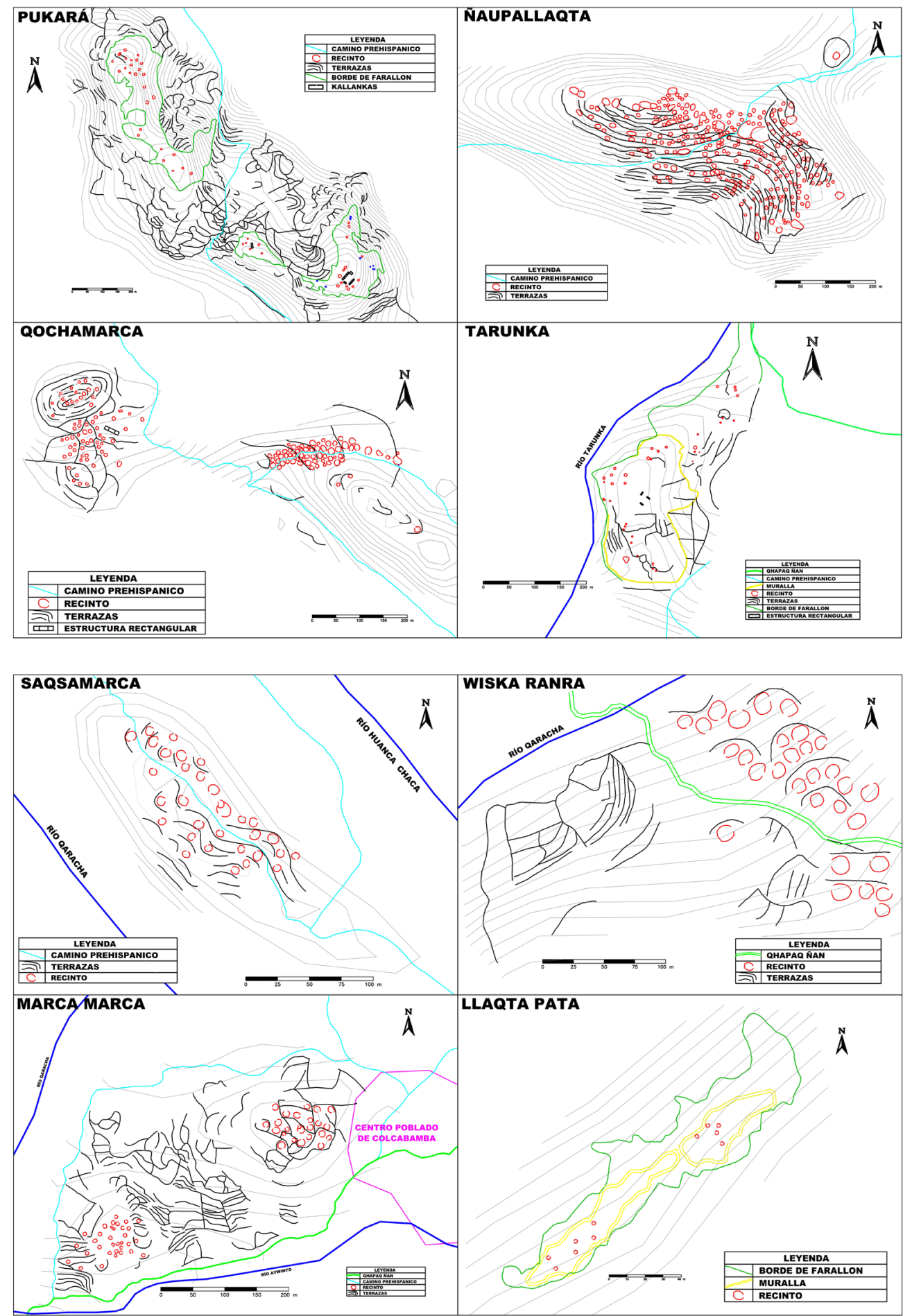

Figura 14. Planimetría de los principales sitios prehispánicos del Alto Qaracha. (Elaborado por Juan Tello y Ricardo González). 
rados a la nación chanka (González Carré, 1992); no obstante, los estudios de Bauer et al. (2013) han establecido el territorio chanka únicamente al valle de Andahuaylas ${ }^{15}$.

La frontera temporal de esta época ha sido establecida en base a una secuencia relativa en base a los estudios de Lumbreras (1974) sobre el material cerámico de esta época en Ayacucho. González Carré et al. (1987) propone cuatro estilos de la cerámica chanka y su ordenamiento a partir de sus rasgos afines con la tradición wari e inca, en lo previo y posterior: Tanta Orqo, Qachisqo, Arqalla y Aya Orqo. La difusión del estilo Arqalla en los asentamientos tardíos ha servido de elemento diagnóstico para identificar la ocupación chanka, sin distinción específica de las etnias: "Arqalla es un grupo cerámico de uso generalizado en todo el territorio chanka" (Gonzalez Carré 1992, p. 59). Está demostrado la amplia distribución del estilo Arqalla en el valle del río Pampas y sus afluentes. Vivanco (1998), confirma la presencia del estilo Arqalla en los sitios tardíos de la cuenca del río Pampas: "La presencia en alto porcentaje de la cerámica Arqalla demuestra que este tipo de vajilla ha sido comúnmente utilizado en la cuenca del Pampas y Qaracha" (p. 180). Las características del material cerámico del alto Qaracha hacen suponer que la poca elaboración de los objetos y su fabricación de baja calidad está relacionada con una finalidad utilitaria, por sus características singulares, la cerámica podría corresponder a los rukanas del Qaracha que confirmaría su posición temporal, aunque esta inferencia es preliminar la correlación del material cerámico nos acercan al estilo arqalla. La sobria alfarería post wari del alto Qaracha parece reflejar las difíciles condiciones de la época. En general, este estilo representa la cerámica de uso común durante el periodo intermedio tardío, se considera que Arqalla es el estilo cerámico difundido por los pueblos altoandinos antes de la presencia inca en la región: "El estilo Arqalla está presente en sitios fortificados, donde hay ausencia de elementos inka" (Valdez, 2002, p. 89).

El estudio de la territorialidad en el alto Qaracha ha permitido validar el sincretismo cultural entre las formaciones tardías y el ecosistema altoandino que dieron soporte al modo de vida rural en la época prehispánica tardía. El control territorial estuvo relacionado con las nuevas estrategias de aprovechamiento de recursos en un territorio de marcado contraste altitudinal. Los pueblos de este periodo están instalados sobre el piso keswa, locación estratégica para el dominio visual del área e ideal para la práctica del control vertical de los pisos ecológicos que se despliegan en las zonas de vida identificadas en el área. La dispersión de poblados en las distintas franjas ecológicas del alto Qaracha, obedece al acceso y explotación de recursos naturales y minerales de la zona, Esto se ve corroborado por la alta dispersión de

15. Estos datos que provienen de contextos excavados revelan mejor la frontera histórico y temporal chanka: "A finales del periodo intermedio tardío estos grupos habían formado un gran centro cultural, unificando a más de una docena de grupos regionales independientes" (Bauer et al., 2013, p. 111). En este sentido, Espinoza Soriano (2017) sostiene que el tópico "Confederación Chanka" es un lapsus que debe ser superado, la evidencia histórica revela que entre los siglos XI y XII el señorío chanka se estableció en Andahuaylas. 
aldeas sobre el piso keswa, relacionados con la explotación agrícola de andenes y sementeras que se despliegan en las quebradas templadas del Qaracha; excepto por dos pueblos -Llaqta Pata y Marca Marca- instalados en la cabecera del alto Qaracha, y cercanos a la fuente de la cantera de obsidiana Quispisisa, los restos de lascas y preformas de artefactos líticos evidencian la intensa actividad de extracción de la obsidiana durante este periodo. Este modo de producción corresponde a una formación social del tipo aldeano, es este hábitat rural la base económica es autosuficiente, en un escenario de complementariedad ecológica de recursos altoandinos que podría definirse como una variante local del control de los nichos ecológicos del Qaracha, un esbozo similar al primer caso de verticalidad planteado por Jhon Murra ${ }^{16}$.

Los asentamientos del alto Qaracha lucen rasgos íntegramente aldeanos con adaptación al medio geográfico, el análisis del espacio y organización de los asentamientos ha permitido distinguir sutiles diferencias en cuanto al diseño urbano, estas diferencias son visibles de acuerdo a la categoría de los poblados. Los sitios fortificados, están instalados sobre fortines con restricciones naturales, estas difíciles condiciones fueron resueltos con la construcción de muros circundantes, aislando del exterior los recintos internos. Los sitios $\operatorname{cimeros}^{17}$ que ocupan la cresta de las montañas, son aldeas extensas con alta densidad de estructuras habitables y acondicionamientos arquitectónicos de muros perimetrales y terrazas escalonadas, este patrón constructivo es similar a lo observado por Vivanco y Valdez (2013) en el curso del río Pampas y Qaracha, de acuerdo a Canziani (2009) estas características son comunes en los poblados tardíos de carácter espontáneo y crecimiento asimétrico. Los sitios bajos ocupan el piso del valle, son pueblos pequeños de apariencia aglutinada instalados sobre sistemas de andenes que cubren las laderas de ambos lados de los contrafuertes del Qaracha.

La arqueología del alto Qaracha nos estaría aclarando el panorama étnico en esta región, la perspectiva histórica es limitada para asignar etnias prehispánicas en áreas específicas. En la cuenca del Qaracha no se ha definido con claridad la identidad de

16. El primer caso consiste en un modelo de verticalidad con rango de alcance local, el control simultáneo de los archipiélagos verticales se producía a través de la dispersión de sitios para obtener diferentes recursos alejados de sus centros principales, tal como lo compartían las etnías pequeñas de Chaupiwaranga en el Alto Marañón (Murra, 1975, p. 62).

17. El enfoque etnohistórico, nos revela con claridad este rasgo aldeano que aún se mantiene en la actualidad en las zonas altas, según la información del corregidor Luis de Monzón: "las casas desta provincia son pequeñas y bajas, hechas a dos aguas, y otras redondas de piedra y barro, sin cal, cubiertas con paja, de rústica proporción". (1881a, p. 176). De la misma forma Cieza de León, al describir los aposentos de los pueblos de altura, nos describe: "Las casas de estos indios, y aun las de todos lo más son de piedra y la cobertura de paja" (2005, p. 217). "Algunos de ellos fueron belicosos, y los pueblos tienen entre sierras altísimas [...]. Las casas todas son de piedra y paja" (2005, p. 244). Las observaciones en los sitios del Alto Qaracha han revelado estructuras con similares características a esta descripción, recintos circulares elaborados de pirca rustica con un pequeño acceso, la cobertura cónica, tal como lo plantea Gonzáles Carré (1992), fue elaborada con viguetas de madero cubiertas con paja ó ichu (stipa ichu). 
estos grupos, aunque los documentos históricos del siglo XVI señalan como área adscrita a los andamarcas y para la época inca existe presencia de grupos de mitimaes foráneos entre los que figuran huancas, xauxas, yauyos, quichuas y aymaraes (Earls, 1980; Earls y Silverblatt, 1979 ; Huertas, 1990, 1998; Salas, 1979, 2000; Urrutia, 2014).

El sitio Pukará, probablemente sirvió como el principal centro administrativo inca en el Qaracha, otro sitio con remanentes del Horizonte Tardío es Qochamarca, un pueblo grande con una arquitectura única de formas rectilíneas puede representar un tampu o quizá algún tipo de sitio de función especial establecido por los incas; ambos sitios están situado al borde de un área lacustre que da paso a la quebrada, y desde su posición natural un lugar con una buena vista de ambas márgenes del río Qaracha. El panorama territorial a una escala local estaría aclarando la identidad de estos grupos a través del correlato material, con frecuencia el marco cronológico de González Carré $(1987,1992)$, autor a quien hemos tomado como referencia para asignar la frontera temporal de estos grupos étnicos. De acuerdo a esta secuencia se considera al estilo arqalla como cerámica de amplia difusión en el alto Qaracha durante el periodo Intermedio Tardío, en algunos sitios aparecen material del Horizonte Tardío en asociaciones con la cerámica local. Este material podría corresponder a la alfarería local durante la influencia inca, la pasta se distingue por ser de color rojo y anaranjado de engobe fino. Por otro lado, creemos que esta generalidad de asociaciones ambiguas estaría simplificando las diversas expresiones materiales del alto Qaracha a un sólo indicador temporal.

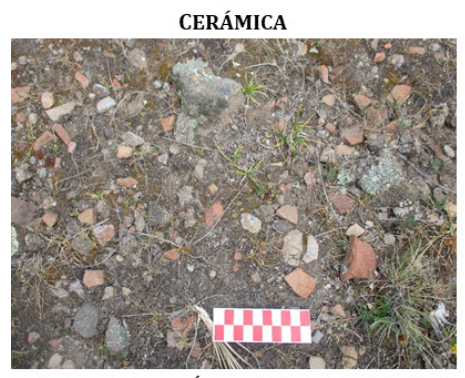

FRAGMENTOS DE CERÁMICA PIT. SITIO: QOCHAMARCA

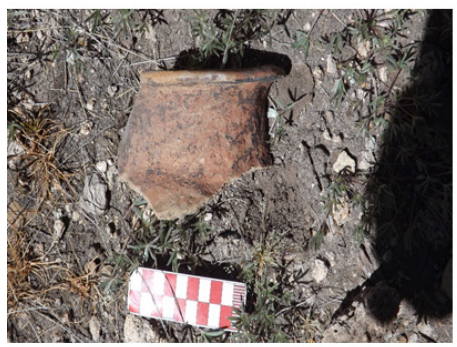

FRAGMENTO DE JARRA HT. SITIO: PUKARA

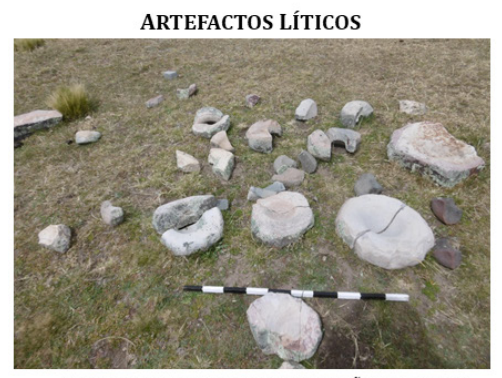

FRAGMENTOS DE MORTERO. SITIO: ÑAUPALLAQTA

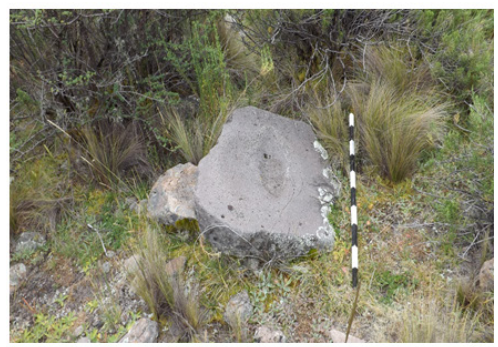

BATÁN. SITIO: QOCHAMARCA

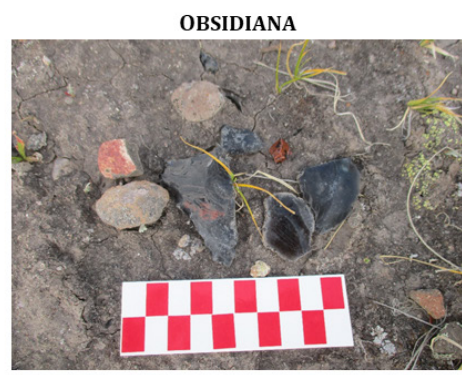

PUNTA DE PROYECTIL. SITIO: LLAQTA PATA

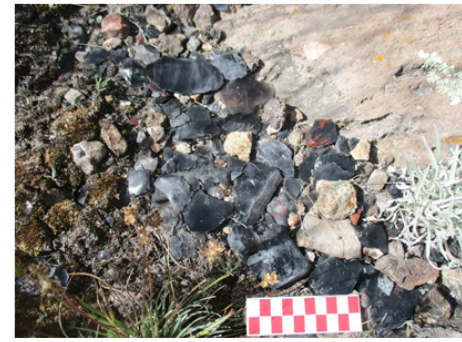

LASCAS DE OBSIDIANA. SITIO: MARCA MARCA

Figura 15. Evidencias materiales en superficie de los sitios prehispánicos del Alto Qaracha. 


\section{CONCLUSIONES}

La función territorial de los pueblos principales del alto Qaracha residía en el tradicional control de las alturas y profundidades del paisaje altoandino. Los poblados se extienden a lo largo de la quebrada, la mayor parte se instalan en las alturas en una posición preferencial, son núcleos urbanos complejos con arquitectura vial, hidráulica, agrícola y pastoril. Los poblados que están en el piso del valle, son de menor tamaño y menos complejos, esparcidos sobre laderas y pequeños promontorios que dominan el fondo de la quebrada, relacionados con las actividades productivas, principalmente talleres de obsidiana y almacenes de productos. La ocupación prehispánica de este periodo se concentra sobre las crestas que se elevan en los contrafuertes del río Qaracha, este paisaje conformaba el principal habitad de este periodo, el modo de vida aldeano estaba acondicionado a este medio rural, el notable escalonamiento ecológico y el acceso a los recursos naturales de las zonas de vida altoandina, permitió el desarrollo de una economía agropastoril.

Desde el enfoque locacional, se postula que el territorio del alto Qaracha responde al nuevo patrón locacional de la época Señoríos Regionales (1100 - 1400 d. C.), consolidado en el contexto de atomización política de latente conflicto, la profusión de pueblos altoandinos es muy predominante respecto la época posterior inca (1400 - 1532 d. C.). Se identifica una red de sitios fortificados y naturalmente defensivos construidos sobre la cresta de las montañas, ocupando alturas entre los 3000 y 4000 m. s. n. m. Esta disposición de los sitios en prominencias topográficas les otorgaba una identidad territorial visible en el paisaje, el intervalo de separación entre las aldeas aumentaba el rango de visibilidad hacia los pisos más elevados del Qaracha. Los sitios presentan un marcado acento aldeano y una falta aparente de planeamiento en su disposición urbana, uno de los factores que no permitió la planificación parece haber sido la accidentada topografía que condicionó arreglos arquitectónicos en espacios limitados. El patrón de asentamiento es idéntico en casi todos los sitios identificados, se trata de conjuntos de edificios circulares erigidos en las cumbres de los cerros protegidos naturalmente, según dos variantes; tipo alveolar concatenado (mesetas) y tipo alveolar en terrazas (pendiente de montaña). Las viviendas y las áreas de actividad se organizan de acuerdo al uso social del espacio, el elemento básico de construcción es la unidad de grupo patio, formado por un grupo de edificios circulares dispuestos alrededor de un patio central, esta disposición tiene analogía con la unidad alveolar de los astos, aunque en menor grado de complejidad. Desde el final del período Intermedio Tardío hasta el Horizonte Tardío, no hubo grandes cambios en el número de sitios de ocupación local definidos como sitios con restos arquitectónicos visibles. Pero algunos lugares muestran evidencia de la presencia imperial con modificaciones de la arquitectura local y la presencia de nuevas formas 
de arquitectura inca y estilos de cerámica tawantinsuyo. Con solo una excepción, en específico el sitio Pukará, no hubo cambios aparentes en el tamaño y complejidad de los asentamientos prominentes, aunque el control y defensa de las cimas de las montañas perdieron importancia y en el Horizonte Tardío sólo parecen haberse concentrado en el sitio Pukará.

Desde la perspectiva ecológica, la ubicación de los poblados a lo largo de las franjas ecológicas identificadas, se relaciona con el control de los diferentes pisos altitudinales en medio de una variabilidad ecológica de fácil transición. En este ambiente, se puede identificar el alto Qaracha como un territorio aldeano en un ecosistema de puna baja en proximidad a la zona agrícola al pie de la escorrentía del río Qaracha e integrado por la actividad pastoril sobre el piso keswa. La elevada posición de los pueblos tardíos ampliaba el rango de visibilidad y dominaba el paisaje circundante. La ubicación estratégica y preferencial de los sitios facilitaba el manejo vertical del territorio y la complementariedad de productos a través del flujo constante de bienes materiales prehispánicos. El escenario sugerido para el alto Qaracha es una red de provisión e intercambios de estos productos a corta y larga distancia, las implicancias económicas de esta red están relacionadas con la intensificación de la actividad agrícola y la adquisición y distribución de recursos minerales. En este contexto, la zona del muestreo sería un enclave altamente productivo y área de provisión para abastecer la circulación interna y el intercambio extra regional de obsidiana, los datos presentados aquí demuestran que la obsidiana Quispisisa permaneció en uso activo durante este período. Así mismo, la presencia de los corrales cerca de unos sitios se atribuye a las grandes estancias pastoriles con un papel importante en el manejo de los rebaños de camélidos. Este escenario se orientaba hacia la autosuficiencia un modelo consistente con el modo de producción altoandino.

Agradecimientos: El artículo ha sido elaborado con la finalidad de explicar parte del proceso histórico de los pueblos actuales del río Qaracha. Agradecemos a la comunidad campesina de Sacsamarca, por las facilidades brindadas en las exploraciones; de manera especial al ex alcalde del Distrito de Sacsamarca Bartolomé Fernández y al incansable viajero Wilber Cancho por la guía y compañía en el recorrido del área.

\section{REFERENCIAS BIBLIOGRÁFICAS}

Arkush, E. (2012). Los pukaras y el poder: Los Collas en la cuenca septentrional del Titicaca. Arqueología de la cuenca del Titicaca, Perú (pp. 295-320).

Bauer, B., Araoz, M. y Kellett, L. (2013). Los Chankas. Investigaciones Arqueológicas en Andahuaylas (Apurímac, Perú). Instituto Francés de Estudios Andinos, Lima. 
Bandera, Damián de la (1881). Relación de la disposición y calidad de la Provincia de Guamanga, llamada San Juan de la Frontera. Relaciones geográficas de Indias, Perú. Tomo I (pp. 96-104). (Original publicado en 1557).

Burger, R. y Asaro, F. (1977). Trace Element Analysis of Obsidian Artifacts from the Andes: New Perspectives on Prehispanic Economic Interaction in Perú and Bolivia. Lawrence Berkeley Laboratory Report, 6343, 1-88.

Burger, R. y Asaro, F. (1979). Análisis de los rasgos significativos en la obsidiana de los Andes Centrales. Revista del Museo Nacional, 43, 281-326.

Burger, R. y Glascock, M. (2000). Locating the Obsidiana Source in the Department of Ayacucho, Perú. Latin American Antiquity, 11, 258-268.

Canziani, J. (2009). Ciudad y Territorio en los Andes. PUCP, Fondo Editorial.

Carbajal, P. de (1881). Descripción de la provincia de Vilcas Guaman. Relaciones geográficas de Indias, Perú. Tomo I (pp. 145-168). (Original publicado en 1586).

Cavero, Y. (2010). Inkapamisan: Ushnus y Santuarios Inka en Ayacucho. Ayacucho, Mercantil Ayacucho E.I.R.L.

Cieza de León, P. (1880). Crónica del Perú. Segunda Parte. Madrid, Biblioteca Hispano-Ultramarina.

Cieza de León, P. (2005). Crónica del Perú. El Señorío de los Incas. Biblioteca Ayacucho. (Original publicado en 1553).

Contreras, D., Tripcevich, N. y Cavero, Y. (2012). Investigaciones en la fuente de la obsidiana tipo Quispisisa, Huancasancos - Ayacucho. Investigaciones Sociales, 16(28), 122-31.

D'altroy, T. (2015). El poder provincial en el imperio inka. Instituto de Estudios Peruanos, Lima.

D'altroy, T. y Hastorf, C. (2002). Empire and Domestic Economy. Springer Science.

Earle, T., D'altroy, T., Hastorf, C., Scott, C., Costin, G., Rusell, G. y Sandefur, E. (1987). Archeological field research in the Upper Mantaro valley, Perú: 1982-1983. Investigations of Inca expansión and exchange. University of California.

Earle, T., D’altroy, T., Scott, C., Hastorf, C. y Levine, T. (1988). Sobre la penetración inca en el valle del Mantaro. Boletín de Lima, 59, 39-50.

Earls, J. (1980). Patrones de Jurisdicción y organización entre los Qaracha wankas: una reconstrucción arqueológica y etnohistórica de una época fluida. Ayllu, Etnía y Parcialidad, II Jornada de la Historia con la Antropología Andina, pp. 231-253. 
Earls, J., y Silverblatt, I. (1979). Ayllus y etnías de la región Pampas-Qaracha: El impacto de la conquista inca. Actas del III Congreso Peruano sobre el Hombre y la Cultura Andina. Vol. I, pp. 157-177.

Espinoza Soriano, W. (2017). El reino Chanka. Investigaciones Sociales, 21(38), 139-171. González Carré, E. (1992). Los Señoríos Chankas. Ayacucho, UNSCH.

González Carré, E., Pozzi-Escot, M., Pozzi-Escot, D. y Vivanco, C. (1987). Los Chankas: Cultura Material. Ayacucho, UNSCH.

Hastorf, C., Earle, T., Wright, H.E., LeCount, L., Russell, G. y Sandefur, E. (1989). Settlement Archaeology in the Jauja Region of Perú: Evidence from the Early Intermediate Period throuhg the late intermediate period: A reporto $\mathrm{n}$ the 1986 field season. Andean Past, 2, pp. 81-129.

Jiménez de la Espada, M. (1881). Relaciones geográficas de Indias, Perú. Tomo I. Ministerio de Fomento, Madrid. (Original publicado en 1586).

Huertas, L. (1990). Los Chankas. Proceso disturbativo en los Andes. Historia y Cultura, 20, 11-48.

Huertas, L. (1998). Conformación del espacio social en Huamanga, siglos XV y XVI. Historia, religión y ritual de los pueblos ayacuchanos, 7-28.

Huertas, L., Granada, J. y González Carré, E. (1976). Revisita de los Chocorbos. Ayacucho, UNSCH.

INGEMMET. (1996). Geología de los Cuadrángulos de Huancapi, Chincheros, Querobamba y Chaviña. Lima.

INRENA. (1995). Mapa Ecológico del Perú. Guía Explicativa. Lima, Ministerio de Agricultura.

Isbell, W. (1970). Un pueblo rural ayacuchano durante el Imperio Huari. Actas y Memorias del 39 Congreso Internacional de Americanistas, 3, 89-105.

Lavallée, D. y Julien, M. (1983). Asto: Curacazgo Prehispánico en los Andes Centrales. Lima, Instituto de Estudios Peruanos.

Lumbreras, L. G. (1959). Sobre los Chankas. Actas y Trabajos del II Congreso Nacional de Historia del Perú, T. I, 211-241.

Lumbreras, L. G. (1974). Las Fundaciones de Huamanga. Club Huamanga.

Matos, R. (1959). Los Wanka: Datos históricos y arqueológicos. Actas y Trabajos de II Congreso Nacional de Historia del Perú: Época Prehispánica. T. II, 425-447.

Matos, R. (1966). La economía durante el Periodo de Reinos y Confederaciones en Mantaro, Perú. Actas y Memorias del XXXVI Congreso Internacional de Americanistas, 2, 116-128. 
Matos, R. y Parsons, J. (1979). Poblamiento prehispánico de la cuenca del Mantaro. Arqueología Peruana (pp. 157-171). Lima, UNMSM.

Meddens, F.y Schreiber, K. (2010). Inca strategies of control: a comparison of the Inca occupations of Soras and Andamarca Lucanas. Naupa Pacha, 30(2), 127-166.

Meddens, F. y Vivanco, C. (2005). The Chanka confederation: Political myth and archeological reality. Xama, 15(18), 73-99.

Monzón, L. de (1881a). Descripción de la tierra del repartimiento de Atunsora. Relaciones geográficas de Indias, Perú. T I, 169-178. (Original publicado en 1586).

Monzón, L. de. (1881b). Descripción de la tierra del repartimiento de San Francisco de Atunrucana y Laramati. Relaciones geográficas de Indias, Perú. Tomo I, 179196. (Original publicado en 1586).

Monzón, L. de. (1881c). Descripción de la tierra del repartimiento de los Rucanas Antamarcas. Relaciones geográficas de Indias, Perú. Tomo I, 197-216. (Original publicado en 1586).

Murra, J. (1975). Formaciones económicas y políticas del mundo andino. Lima, Instituto de Estudios Peruanos.

ONERN. (1976). Mapa Ecológico del Perú. Guía Explicativa. Lima.

Parsons, J., Hastings, C. y Matos, R. (2000). Prehispanic settlement patterns in the Upper Mantaro and Tarma drainages, Junin, Perú. Vol. I. The Tarama-Chinchaycocha Region. University of Michigan.

Saintenoy, T. (2016). Arqueología de las llaqtas del valle del Apurímac: Contribución al estudio de la territorialidad de las comunidades aldeanas serranas en los Andes prehispánicos. Chungará, Revista de Antropología Chilena, 48(2), 1-26.

Salas, M. (1979). De los obrajes de Canaria y Chincheros a las comunidades indígenas de Vilcashuamán. Siglo XVI. Talleres Tipo-Offset SESATOR.

Salas, M. (2000). Advenedizos y traspuestos: Los mitmaqkuna o mitimaes de Vilcashuamán en su tránsito de los tiempos del inka al de los Señores de los Mares. Boletín de Arqueología PUCP, 6, 57-78.

Schreiber, K. (1991). Jincamocco: A Huari Administrative Center in the South Central Highlands of Perú. Huari Administrative Structure: Prehistoric Monumental Architecture and State Government, (pp. 199-213). Dumbarton Oaks.

Pulgar Vidal, J. (1996). Geografía del Perú. Las Ocho Regiones Naturales. Lima, Editorial Universo.

Valdez, L. (2002). La alfarería de la época inka en el valle de Ayacucho, Perú. Boletín de Arqueología PUCP, 6, (pp. 395-419). 
Valdez, L. y Vivanco, C. (1994). Arqueología de la Cuenca del Caracha, Ayacucho, Perú. Latin American Antiquity, 5, 144-157.

Vega Centeno, R. (2019). Economías tardías: Producción y distribución en los Andes Centrales antes y durante la expansión del Tawantinsuyo (900-1532 d. C.). Historia económica del antiguo Perú, 403-514. Lima, IEP-BCR.

Urrutia, J. (2014). Aquí nada ha pasado. Huamanga, Siglos XVI-XX. Lima, Instituto Francés de Estudios Andinos.

Vivanco, C. (1998). El poblamiento prehispánico en la cuenca del Pampas y Qaracha, Sarhua (Ayacucho). Conchopata, 1, (pp. 163-190).

Vivanco, C. (2003). Pukará: un Poblado Chanka Fortificado en la Cuenca Superior de Qaracha, Ayacucho. Investigaciones en Ciencias Sociales, 1, 121-142.

Vivanco, C. (2005). Tiempos de purun-runas en la cuenca de Qaracha: violencia en la época prehispánica tardía. Investigaciones en Ciencias Sociales, 2, 103-128.

Vivanco, C. (2013). Pukará Llaqtakuna. Pueblos fortificados del periodo intermedio tardío en Ayacucho, Perú. Investigación, 21(2), 317-326. 


\section{SOBRE LOS AUTORES}

\section{MARCO ANTONIO TAQUIRI GONZÁLEZ}

Licenciado en Arqueología por la Universidad Nacional San Luis Gonzaga. Diplomado en Gestión del Patrimonio y de la Cultura por Universidad Nacional San Cristóbal de Huamanga. Diplomado en Gestión de Relaciones Comunitarias y Responsabilidad Social por la Facultad de Ciencias Económicas de la Universidad Nacional Mayor de San Marcos. Ha publicado recientemente el artículo: "Ñaupallacta un poblado prehispánico de patrón local e inca. Cuenca alta del río Acarí", en la Revista Haucaypata. Investigaciones Arqueológicas del Tahuantinsuyo. Actualmente, consultor y arqueólogo independiente.

\section{JUAN MANUEL TELLO QUITO}

Bachiller en Arqueología por la Universidad Nacional San Luis Gonzaga. Diplomado en Seguridad y Salud Ocupacional en el sector Minero e Industrial en Consulting Safety Team (Consultoría en recursos Humanos y Seguridad ocupacional). Actualmente, arqueólogo independiente.

\section{RICARDO GONZALEZ ALVARADO}

Licenciado en Arqueología por la Universidad Nacional San Luis Gonzaga. Diplomado en Ciencias Forenses por el Instituto Nacional de Investigación Forense. Operador-Piloto RPAS por la Dirección General de Aeronáutica Civil del Ministerio de Transportes y Comunicaciones. Actualmente, secretario general del Instituto de Paleontología, Arqueología y Medio Ambiente - IPAMA. 